\title{
Turnover of Newborn Olfactory Bulb Neurons Optimizes Olfaction
}

\author{
Aurélie Mouret, ${ }^{1,2}$ Gabriel Lepousez, ${ }^{3}$ Julien Gras, ${ }^{1,2}$ Marie-Madeleine Gabellec, ${ }^{1,2}$ and Pierre-Marie Lledo ${ }^{1,2}$ \\ ${ }^{1}$ Institut Pasteur, Perception and Memory Unit, ${ }^{2}$ Centre National de la Recherche Scientifique, Unité de Recherche Associée 2182, F-75724 Paris, France, \\ and ${ }^{3}$ Inserm Unité Mixte de Recherche 894, Centre de Psychiatrie et Neurosciences, Université Paris Descartes, F-75014 Paris, France
}

\begin{abstract}
Postdevelopmental neurogenesis occurs in the olfactory bulb (OB), to which new interneurons are continuously recruited. However, only a subset of the adult-generated interneurons survives, as many undergo programmed cell death. As part of homeostatic processes, the removal of new neurons is required alongside the addition of new ones, to ensure a stable neuron number. In addition to a critical role in tissue maintenance, it is still unclear whether this neuronal elimination affects the functioning of adult circuits. Using focal drug delivery restricted to the $\mathrm{OB}$, we investigated the significance of programmed cell death in the adult $\mathrm{OB}$ circuits. Cell death was effectively blocked by the broad-spectrum caspase inhibitor benzyloxycarbonyl-Val-Ala-Asp(OMe)-fluoromethylketone (zVAD). The zVAD effect differed with newborn interneuron location, either in the superficial (periglomerular cells) or in the deep (granule cells) OB layers. Furthermore, whereas sensory experience potentiated the effect of zVAD on the survival of new granule cells, it had no additional effect on the survival of new periglomerular cells. Thus, distinct mechanisms control the survival/elimination decision of newborn interneuron subtypes. However, zVAD had no effect on the olfactory sensory neurons projecting to the bulb. Remarkably, psychophysical analyzes revealed that a normal rate of new neuron elimination was essential for optimal odorant exploration and discrimination. This study highlights the importance of cell elimination for adjusting olfactory performance. We conclude that adult-generated OB interneurons are continually turned over, rather than simply added, and the precise balance between new and mature interneurons, set through active selection/ elimination processes, is essential for optimizing olfaction.
\end{abstract}

\section{Introduction}

In lower vertebrates, adult neurogenesis continually supplies additional neurons capable of regenerating entire brain tissues. In contrast, neurogenesis is restricted to a small number of regions of the adult mammalian brain, in which it generates neurons mainly for replacement purposes. Tens of thousands of new cells are generated and reach the mammalian olfactory bulb $(\mathrm{OB})$ each day (Alvarez-Buylla et al., 2001). However, only a small percentage of these cells persist long enough to differentiate into mature interneurons. Previous studies have shown that only $50 \%$ of the new neurons migrating into the bulb survive for longer than a month after their initial generation and differentiate principally into granule and periglomerular cells (Petreanu and AlvarezBuylla, 2002; Yamaguchi and Mori, 2005; Alonso et al., 2006; Mouret et al., 2008).

At first glance, neurogenesis in adult mammals would appear to be a wasteful process as most of the newly generated neurons

\footnotetext{
Received July 14, 2009; accepted Aug. 5, 2009.

This work was supported by Agence Nationale de la Recherche Grant ANR-2007 SEST-01411, Fondation pour la Recherche Médicale "Equipe FRM," Groupe Arpège, and Ecole des Neurosciences de Paris. A.M. and G.L. are supported by grants from the Ecole Normale Supérieure. Our laboratory is a member of the Network of European Neuroscience Institutes (LSHM-CT-2005-019063). We thank Ariane Salpin for helping us with preliminary behavioral experiments, Mariana Alonso for advice on the osmotic minipump implantation technique, Jean-Cristophe Olivo-Marin's laboratory for helping with quantitative imaging, and Sebastien Wagner for designing the computerdriven olfactometers.

Correspondence should be addressed to Dr. Pierre-Marie Lledo, Institut Pasteur, Perception and Memory Unit, 25 rue du Dr. Roux, F-75724 Paris Cedex 15, France. E-mail: pierre-marie.lledo@pasteur.fr.

D0I:10.1523/JNEUROSCI.3383-09.2009

Copyright $\odot 2009$ Society for Neuroscience $\quad$ 0270-6474/09/2912302-13\$15.00/0
}

undergo programmed cell death a few weeks after birth. This process resembles the early developmental mechanisms occurring during embryogenesis, in which cells with aberrant synaptic connections are actively eliminated to allow the sculpting of functional neuronal networks (Yuan and Yankner, 2000). According to this model, adjustments to the rate of cell death may represent an as yet unexplored active process of mature circuits capable of integrating new neurons throughout life. However, despite the clear importance of the process of elimination during embryogenesis, only a limited number of factors, such as Bax (Sun et al., 2004; Kim et al., 2007) and NMDA receptors (Tashiro et al., 2006), have been identified in the control of survival rates for adult-generated neurons. Data are accumulating to suggest that sensory experiences exert their effects on adult neurogenesis mostly by increasing cell survival (Alonso et al., 2006; Mouret et al., 2008), but the functional consequence of adjusting cell elimination remains unknown.

In this study, we addressed this question by assessing the olfactory performance of mice treated with a pancaspase inhibitor [benzyloxycarbonyl-Val-Ala-Asp(OMe)-fluoromethylketone $(z V A D)]$. Caspase inhibitors have been used as effective therapeutic agents to reduce neurodegeneration in various neurodegenerative models. Among them, zVAD has been successfully used to prevent caspase activation in many studies (Li et al., 2000; Scholz et al., 2005; Dupret et al., 2007; Thompson and Brenowitz, 2009), and neuronal death is mediated by the activation of caspases in many brain regions, including the OB (Yuan et al., 2003; Yamaguchi and Mori, 2005). Moreover, zVAD is well tol- 
erated when administered for prolonged periods (Chen et al., 2000; Li et al., 2000).

As the $\mathrm{OB}$ is intimately involved in the first stage of sensory information processing, we hypothesize that both the integration and elimination of interneurons are directly involved in this process. This assumption gives rise to a fundamental question: Is the death of new neurons necessary for the correct processing of olfactory information? We found that a precise rate of new neuron elimination was essential for optimizing odor exploration and discrimination, and thus conclude that the continual addition and elimination of new neurons are both essential.

\section{Materials and Methods}

Mice

Two-month-old male C57BL/6J mice (Janvier) were maintained under a $12 \mathrm{~h}$ light/dark cycle. For the study of olfactory sensory neurons (OSNs), 2 - to 3-month-old male mouse odorant receptor gene number 23 (MOR23)-IRES-tauGFP mice were used (Vassalli et al., 2002). After osmotic minipump implantation, the animals were housed individually. Water intake was restricted to $1-2 \mathrm{ml} / \mathrm{d}$ during olfactory training, to maintain weight at $85 \%$ the prerestriction baseline. All procedures were performed in accordance with the Charter of Fundamental Rights of the European Union (2000/C 364/01), the European Communities Council Directive of 24 November 1986 (86/609/EEC), and European Union guidelines, and were reviewed and approved by our Institutional Animal Welfare Committee.

\section{BrdU injections}

Mice were injected intraperitoneally with bromodeoxyuridine (BrdU) (75 mg/kg; Sigma-Aldrich). They received four injections, $2 \mathrm{~h}$ apart, on the same day, and were perfused 16 or $30 \mathrm{~d}$ later.

\section{zVAD infusion}

The synthetic peptide zVAD (at a concentration of $2 \mathrm{~g} / \mathrm{L}$; Calbiochem) in saline solution $(\mathrm{NaCl}, 9 \mathrm{~g} / \mathrm{L}$; DMSO, $1.5 \%)$, or vehicle alone was infused between the two OBs via a cannula (Alzet Brain Infusion Kit III; 1-3 mm) connected to an osmotic minipump (Alzet; model 1002) (flow rate, 0.25 $\mathrm{L} / \mathrm{h} ; 15 \mathrm{~d}$ ), to avoid damage to the bulbs. The flow rate used was determined beforehand, using $1 \%$ Chicago blue dye in saline to visualize the diffusion of the solution throughout both OBs without the invasion of other neural structures.

Mice were anesthetized by an intraperitoneal injection of $200 \mu \mathrm{l}$ of a mixture of ketamine (Imalgene; $1.5 \%$ in PBS) and xylazine (Rompum; Bayer Health Care; $0.025 \%$ in PBS). They were then mounted in a Kopf stereotaxic apparatus (Harvard Apparatus). The cannula was implanted stereotaxically between the two OBs (at the coordinates: $4.5 \mathrm{~mm}$ anterior to bregma, $0 \mathrm{~mm}$ lateral of midline, and $1.5 \mathrm{~mm}$ from brain surface) and was connected to the osmotic minipump, which was inserted subcutaneously. Pumps were weighed before implantation and at the end of the experiment to ensure that they had delivered their entire contents. The correct placement of the cannula was checked after death, by histological examination.

\section{Tissue preparation}

Under deep anesthesia (sodium pentobarbital; $100 \mathrm{mg} / \mathrm{kg}$; sanofiaventis), mice were killed by the intracardiac perfusion of $40 \mathrm{ml}$ of saline $(\mathrm{NaCl}, 0.9 \%)$ supplemented with heparin $\left(5 \times 10^{3} \mathrm{U} / \mathrm{ml}\right)$ at $37^{\circ} \mathrm{C}$, followed by $200 \mathrm{ml}$ of cold fixative ( $4 \%$ paraformaldehyde in $0.1 \mathrm{M} \mathrm{PBS}, \mathrm{pH}$ 7.4). Olfactory epithelia (OEs) and olfactory bulbs (OBs) were removed, postfixed by incubation in the same fixative at $4^{\circ} \mathrm{C}$ overnight. OEs were cryoprotected by incubation in 30\% sucrose in PBS for $24 \mathrm{~h}$, and then embedded in Tissue-tek (Sakura Finetek), quickly frozen with ice-cold isopentane, and stored at $-80^{\circ} \mathrm{C}$. OE $16-\mu \mathrm{m}$-thick coronal sections were cut using a cryostat, thaw-mounted onto coated glass slides (Superfrost Plus), and stored at $-20^{\circ} \mathrm{C}$. OB coronal $40 \mu \mathrm{m}$ serial sections were cut with a vibratome (VT100S; Leica) and collected in PBS (0.1 M), pH 7.3.

\section{Immunohistochemistry}

Immunostaining was performed on free-floating $40 \mu \mathrm{m}$ coronal sections for $\mathrm{OB}$ and on fixed sections for OE. Slices were processed for BrdU,
BrdU/neuron-specific nuclear protein (NeuN), olfactory marker protein (OMP) $/ 4^{\prime}, 6^{\prime}$-diamidino-2-phenylindole (DAPI), green fluorescent protein (GFP)/DAPI, and growth association protein 43 (GAP43)/OMP/ DAPI labeling. The primary antibodies used were a rat monoclonal antiBrdU antibody (1:200; Oxford Biotech), a mouse monoclonal antiNeuN antibody (1:200; Millipore Bioscience Research Reagents), a goat polyclonal anti-OMP antibody (1:2000; kindly provided by Dr. F. Margolis, University of Maryland, Baltimore, MD), a rabbit polyclonal anti-GFP antibody (1:1000; Invitrogen), and a mouse monoclonal anti-GAP43 antibody (1:200; Sigma-Aldrich). BrdU-labeled cells were detected with a peroxidase-based detection system (ABC Systems; Vector Laboratories), using biotinylated donkey anti-rat IgG antibodies (1:200; Vector Laboratories) and DAB (0.05\%; Sigma-Aldrich) as the chromogen. For immunofluorescence detection, the secondary antibodies used were species-specific (1:1000; Alexa-conjugated goat anti-rat 568, goat anti-mouse 488, donkey anti-goat 568, or goat anti-rabbit 488; Invitrogen).

\section{Image acquisition}

For light microscopy (BrdU staining), a $20 \times$ objective was used to reconstruct images of each section (Compix Imaging; Hamamatsu Photonics). A microscope (Zeiss) equipped with an apotome and Axiovision 4.6 software was used to acquire fluorescence images. A $25 \times$ objective was used to reconstruct images of each section and $z$-sectioning was performed at $5 \mu \mathrm{m}$ intervals. The phenotype of $\mathrm{BrdU}^{+} / \mathrm{NeuN}^{+}$cells was confirmed using a $63 \times$ objective for $z$-sectioning at $1 \mu \mathrm{m}$ intervals on all double-positive cells. The colocalization of markers was then confirmed by studying merged images for staining in a given cell in each of the $x y$-, $x z-$, and $y z$-planes, in the orthogonal view. Sections were coded blind until the completion of data analysis.

Analysis of $\mathrm{BrdU}^{+}$cells in the $\mathrm{OB}$

$\mathrm{BrdU}^{+}$cells were counted automatically with a dedicated computer program, using a B3 wavelet filtering approach (Mouret et al., 2008). For each animal, counts were made for one in every three coronal sections for both OBs. We used anatomical landmarks within the OB to align coronal sections from different animals. The rostral landmark, defining the origin of the rostrocaudal axis, contained the first clear mitral cell and external plexiform layers. The accessory OB was used as the caudal landmark and the last section counted contained the first, clear accessory OB. The internal and external borders of the glomerular (GL), external plexiform (EPL), granule cell (GCL) layers and the border of the rostral migratory stream of the $\mathrm{OB}$ were drawn interactively. The program then counted the cells detected in the various zones. Values were given as $\mathrm{BrdU}^{+}$cell density (number of positive cells per square millimeter) and averaged for each group. The percentage of $\mathrm{BrdU}^{+}$cells for which death has been prevented between 16 and $30 \mathrm{~d}$ after BrdU administration was also calculated. For that, the $\mathrm{BrdU}^{+}$cell density calculated for animals perfused at $16 \mathrm{~d}$ was fixed at $100 \%$, and the density calculated for control animals (saline infusion) perfused at $30 \mathrm{~d}$ was fixed at $0 \%$. We then calculated, for animals perfused $30 \mathrm{~d}$ after BrdU administration, the percentage of neurons for which death had been prevented by zVAD action, training or both. This normalized representation made it possible to compare the respective effects of the different treatments ( $\mathrm{zVAD}$, training, zVAD plus training), and to make comparisons between $\mathrm{OB}$ layers.

\section{Analysis of $\mathrm{BrdU}^{+}$cells in the hippocampus}

The number of $\mathrm{BrdU}^{+}$cells was counted under a $40 \times$ microscope objective. Counting was restricted to the granular and subgranular layers of the dentate gyrus. For each mouse, counts were made for one in every fourth $40 \mu \mathrm{m}$ coronal section along the rostrocaudal axis of both dentate gyri. Results were expressed as the number of cells per hippocampus section and averaged for each group.

\section{Analysis of $O E$ thickness}

The thickness of the epithelium was measured as the total distance between the basement membrane and the top of the ciliary layer by examining the structure of the cresyl violet-stained olfactory mucosa. It was also measured from OMP and GAP43 staining. For each labeling (cresyl 
violet or OMP/GAP43/DAPI), we analyzed 12 sections per mouse and measured the OE layer thickness on each side of the septum and on turbinates.

\section{Quantitative analysis of $O M P$ staining in the $O B$}

To determine the intensity of OMP staining in the glomeruli, we used NIH ImageJ (version 1.38x) software. For each animal, we analyzed one in every six coronal sections for both OBs. For each section, glomeruli were delineated by hand and the mean intensity of the staining was calculated by dividing the sum of the gray values of all the pixels (on the red channel) by the overall area (number of pixels). Pixel values are in gray level units in the range of $0-255$.

\section{Electroolfactogram of anesthetized freely breathing mice}

Electroolfactogram (EOG) was recorded in urethane-anesthetized mice $(1.5 \mathrm{mg} / \mathrm{kg}$; Sigma-Aldrich), based on the method of Chaput and Chalansonnet (1997). After a small craniotomy, an electrode (coated platinum wire; 0.2-0.5 M 2 ; Phymep) was inserted $1 \mathrm{~mm}$ anterior to the nasofrontal suture and $1 \mathrm{~mm}$ lateral to the midline (reference to a skull screw). Signals were amplified, filtered $(0-50 \mathrm{~Hz})$, and stored on a personal computer using CED-1401 interface and Spike2 software (CED). Pure air or amyl acetate ( $1 \%$ in odorless mineral oil; Sigma-Aldrich) was delivered using a custom-made olfactometer $(100 \mathrm{ml} / \mathrm{min})$. Odors were delivered 10 times for $10 \mathrm{~s}$ at $4 \mathrm{~min}$ intervals. The maximum amplitudes of odor-evoked responses and the amplitude ratio between odor and pure air responses were measured using Spike2 and averaged for each animal.

\section{Spontaneous olfactory discrimination}

Apparatus. All habituation experiments took place in a test cage. A stainless-steel grate with a plastic mesh through which only olfactory cues could pass, and on which mice moved freely during the test session, covered a small chamber $(2 \mathrm{~cm}$ high). Odors were presented by placing $20 \mu \mathrm{l}$ of the odor stimulus on a $6 \mathrm{~mm}$ circle of filter paper (Whatman 1). Odorants were freshly prepared before each experiment. Six sets of two odorants each were used (supplemental Table 1, available at www. jneurosci.org as supplemental material), and all odorants were diluted in mineral oil at a concentration of $10^{-3}$. The filter paper was placed under the grate, in the chamber, so that mice could smell the odorant but not see the filter paper. This procedure also made it possible for the observer to change the odor stimulus without disturbing the animal. The paper was always placed in the same position under the grate. The mice were familiarized with the apparatus $3 \mathrm{~d}$ before the test. No conditioning or food deprivation was performed before this study. The mineral oil used for odor dilution was used during familiarization. The test cage was cleaned and dried before the testing of each mouse.

Habituation/dishabituation test. Our olfactory habituation/dishabituation task was designed to assess the degree to which mice spontaneously discriminated odorants, by habituating the mice to one odorant $(\mathrm{H})$ and then measuring the magnitude of their novelty response to another odorant $(\mathrm{T})$. At the beginning of each test, the mouse was placed in the test cage for a $10 \mathrm{~min}$ habituation period and presented with mineral oil. The odorants were then presented for periods of $2 \mathrm{~min}$, separated by $5 \mathrm{~min}$ intervals. The habituation odorant was first presented during four successive trials. In the fifth trial, the mouse was exposed to a different odorant (test odorant). The test odorants used differed in their structural and perceptual similarity to the habituation odorant. A fifth presentation of the habituation odorant was then performed (sixth trial) to ensure that mice were still habituated to this odorant. During each trial, we measured the time the mouse spent sniffing the odorant. The mouse was considered to be investigating the odor whenever it had its nose on the mesh above the paper filter. A progressive decrease in investigation time across the four presentations of the habituation odorant indicated that the mouse was able to recognize that odorant. We confirmed that the mouse was habituated to the odorant, by checking that the investigation time during the fourth presentation of the habituation odorant was significantly shorter than that during the first presentation. We also checked that the mouse explored the odorant for similar amounts of time during its fourth and fifth presentation. We considered the mouse to be able to discriminate between odors when it spent significantly more time explor- ing the new olfactory stimulus $(\mathrm{T})$ during the fifth exposure than the familiar olfactory stimulus $(\mathrm{H})$ during the fourth exposure. On the basis of previous studies, we selected test odorants similar or dissimilar to the habituation odorants, which we expected mice to be able or not able to discriminate. Each mouse was tested on one odor set per day, and the order of presentation of odor sets was randomized and counterbalanced.

\section{Rewarded olfactory discrimination}

Behavioral apparatus. Mice were trained in identical custom-built computer-controlled eight-channel olfactometers. Briefly, solenoid pinch valves controlled air streams, and odors were generated by passing a $50 \mathrm{cc} / \mathrm{min}$ stream of air over the surface of mineral oil-diluted odorants in disposable $50 \mathrm{ml}$ centrifuge tubes. This odorized air was diluted by a factor of 40 in clean air before its introduction into an odor-sampling tube in the mouse operant chamber. Before use of a new odorant, the olfactometer was washed with $95 \%$ ethanol and air-dried. Each odorant and odorant concentration was maintained in its own saturator tube, and the liquid odorant was refreshed daily. An infrared beam monitors the head insertion into the odor port.

Odorants. The odorants used and their rated purities were amyl acetate (99\%), hexyl acetate (99\%), anisole (99\%), cineole (98\%), (+)-limonene (98\%), (-)-limonene (99\%), (+)-carvone (98.5\%), (-)-carvone (99\%), linalool (97\%), and $\beta$-ionone (96\%). Odorants were purchased from Sigma-Aldrich and were diluted on a per volume basis with odorless mineral oil to the desired concentration, and $10 \mathrm{ml}$ of solution was used as the odorant source in the odor saturation tubes. Odorant concentrations are given as the liquid dilution of the odorant in the saturator tubes, and the stimuli used in training were designated by the name of the odorant and its liquid dilution. The $50 \mathrm{cc} / \mathrm{min}$ odorant vapor from the saturator tube was mixed with $1950 \mathrm{cc} / \mathrm{min}$ clean air before its introduction into the sampling port. Thus, the odor concentration delivered to the sampling port was $2.5 \%$ that of the head space above the liquid odorant.

Pretraining procedures. Partially water-deprived mice were trained, using a go/no-go paradigm in identical custom-built computer-controlled eight-channel olfactometers (Mouret et al., 2008). Standard operant conditioning methods were used to train mice to insert their snouts into the odor sampling port and to respond by licking the water delivery tube (located within the odor sampling port) in the presence of an odorant. The "odorant" used in the pretraining was the mineral oil used for odor dilution. The mice initiated each trial by breaking the light beam positioned across the odor sampling port. This led to the opening of an odor valve and of a diversion valve directing all airflow away from the sampling tube. This resulted in the odorant vapor being combined with the main air stream and the diversion of the main air stream to an exhaust path. The diversion valve relaxed $1 \mathrm{~s}$ later, and the odor stimulus was presented to the odor sampling port. The stimulus valve relaxed $2 \mathrm{~s}$ later, thus terminating delivery of the odor. Reward delivery depended on the mouse keeping its snout in the odor sampling port and licking the water delivery tube in seven or more of the last ten $0.2 \mathrm{~s}$ periods of the $2 \mathrm{~s}$ odor presentation period. Trials in which the mouse did not keep its snout in the odor sampling port for at least $0.1 \mathrm{~s}$ after odor onset were aborted and counted as short sample trials. A $5 \mu$ l water reward was delivered if the mouse satisfied the response criterion. The mouse had then to retract its head (the beam was resealed) and wait at least $5 \mathrm{~s}$ (intertrial interval between the last beam resealing and the new beam break) before initiating a new trial. All mice underwent three such pretraining sessions (of 30 min each) before training.

Training procedures. Mice were trained to respond to the presence of an odor [positive stimulus $(\mathrm{S}+)$ ] by licking the water delivery tube (located within the odor sampling port) and to refrain from responding to the presence of another odor [negative stimulus $(S-)$ ]. In each trial, a single stimulus ( $\mathrm{S}+$ or $\mathrm{S}-$ ) was presented. If the response criterion was met in $S+$ trials, a $5 \mu$ ldroplet of water was given as a reward and the trial was scored as a hit, whereas failing to meet the response criterion was scored as a miss. Meeting the response criterion in S- trials was scored as a false alarm, and failing to make a criterion response was scored as a correct rejection (CR). S + and $\mathrm{S}-$ trials were presented in a modified random order, such that each block of 20 trials contained equal numbers 
of each type of trial and no one type of trial was presented more than three times consecutively. The percentage of correct responses was determined for each block of 20 trials [ (hits + CR $) / 20 \times 100]$. Scores $>85 \%$ implied that mice had correctly learned to assign the reward value of the $\mathrm{S}+$, and the nonreward value of the $\mathrm{S}-$. The trial procedures were identical with those used in the initial pretraining sessions. All trained mice underwent a session of 10 blocks (200 trials) per day, during the training period. For each block, the mean behavioral performance (percentage of correct responses) was calculated for each group. For each task ( $=10$ blocks), the individual mean behavioral performances were calculated, and the daily mean behavioral performance was then calculated and averaged for each group.

\section{Calculating the discrimination times}

For each trial, during the $2 \mathrm{~s}$ odor presentation, the licking pattern of the mouse was registered. Each $0.2 \mathrm{~s}$ period was a segment of the response and the number of segments during which the animal was licking was measured. Trials were counted as correct if the animal licked continuously (in seven or more of the last ten $0.2 \mathrm{~s}$ periods of the $2 \mathrm{~s}$ odor presentation period) on presentation of an $\mathrm{S}+$ odor or did not lick continuously with an $\mathrm{S}-$ odor. At the beginning of the $2 \mathrm{~s}$ odor presentation, animals could not recognize the odorant presented, and their licking frequencies were thus identical for both stimuli. There was no correlation between this initial licking frequency and the subsequent discrimination time of a mouse (data not shown). After this initial step, mice increased the licking rates when recognizing $\mathrm{S}+$, to get the water reward, and stopped licking to retract their head when recognizing $S-$ (see Fig. $5 A$ ). The licking patterns in response to $S+$ or to $S-$ thus became different when animals had discriminated between the two odorants presented.

Discrimination times were calculated for each mouse, for each task, as follows. First, for each block ( $=20$ trials), the probability of licking was calculated for each of the $0.2 \mathrm{~s}$ periods of the $2 \mathrm{~s}$ odor presentation, separately for $\mathrm{S}+$ and $\mathrm{S}-$ responses. We analyzed only the blocks for which the performance of the mouse was above the performance criterion. For these blocks, we extracted the successful trials, corresponding to hits for S+ responses and CR for S- responses. For a given task, the probability of licking of the different blocks was then averaged for each $0.2 \mathrm{~s}$ period separately for $\mathrm{S}+$ and $\mathrm{S}-$ responses, and the values were plotted to visualize the discrimination time of the mouse. It corresponded to the time at which a stable, significant difference between the licking probabilities for $\mathrm{S}+$ and $\mathrm{S}-$ appeared. The discrimination times were then averaged for the different groups of mice.

\section{Olfactory discrimination learning sessions}

Mice trained for 2 weeks were given intensive odor discrimination training with multiple odorants. This intensive olfactory training was performed to compare the effects of $\mathrm{zVAD}$ treatment, and of a training period, on neuronal survival. The following tasks were also used to assess the effects of blocking cell death on rewarded discrimination tasks. Mice learned to discriminate between $1 \%$ anisole and $1 \%$ cineole, between $1 \%$ $\beta$-ionone and $1 \%$ linalool, between $1 \%(+)$-limonene and $1 \%(-)$ limonene, and between $1 \%(+)$-carvone and $1 \%(-)$-carvone. They performed each of these tasks on $2 \mathrm{~d}$. Mice were then trained to discriminate between $1 \%(+)$-carvone and a mixture of $1 \%(+)$-carvone and $1 \%$ $(-)$-carvone. The first mixture was composed of $80 \%$ of $(+)$-carvone and $20 \%$ of $(-)$-carvone. In each successive task, the same procedures were followed, but the concentration of $(-)$-carvone in the mixture was sequentially reduced in separate sessions (one per day) to 5, 2, 1.5, 1, 0.1, and $0.001 \%$.

We assessed discrimination times during sessions in which performance exceeded the performance criterion. The tasks used were $1 \%$ anisole versus $1 \%$ cineole, $1 \%$ amyl acetate versus $1 \%$ hexyl acetate, $1 \%$ $\beta$-ionone versus $1 \%$ linalool, $1 \%(+)$-limonene versus $1 \%(-)$ limonene, and $1 \%(+)$-carvone versus $1 \%(-)$-carvone. Each mouse was tested on one particular task per day, and the order of presentation of the tasks was randomized and counterbalanced.

\section{Olfactory memory}

Short-term memory. We determine the time over which mice were able to discriminate between two odorants and to remember their value (re- warded or nonrewarded). The mice learned to discriminate between $1 \%$ anisole and 1\% cineole and were exposed to the same task again, 24 and $96 \mathrm{~h}$ later. Between the two memory tests, mice underwent interference learning [they learned a different task: $1 \%(+)$-limonene vs $1 \%(-)$ limonene] to increase the difficulty of memorization. For the memory tests, the procedures of the olfactory discrimination task were identical with those previously described for training, except for the length of the session (only 2 blocks) and for the water reward. Mice were given no reward and, thus, could only succeed in the task if they remembered it correctly.

Long-term memory. Mice were subjected to $9 \mathrm{~d}$ of different olfactory discrimination tasks. Then, they learned to discriminate between $1 \%$ $(+)$-carvone and $1 \%(-)$-carvone, and this task was consolidated on 4 consecutive days. One month later, their memory was tested. The mice were partially deprived of water $4 \mathrm{~d}$ before the test. The memory test session was identical with that used for the short-term memory test.

\section{Statistical analysis}

In all cases, data were expressed as mean values \pm SEM. All statistical analyses were performed with StatView 5.0, with $p<0.05$ considered significant. The density of $\mathrm{BrdU}^{+}$cells surviving various numbers of days after $\mathrm{BrdU}$ injection, the percentage of $\mathrm{BrdU}^{+}$cells for which death has been prevented, the percentage of $\mathrm{BrdU}^{+} / \mathrm{NeuN}^{+}$cells, the maximum amplitude, and the amplitude ratio between odor and pure air of EOG, the OMP staining intensity, investigation times during spontaneous behavior, and discrimination times were all compared between groups using two-tailed Student's $t$ tests for independent groups. This test was also used to determine the discrimination time for each mouse performing a go/no-go task, by comparing the licking probabilities for $\mathrm{S}+$ and $\mathrm{S}-$. The respective effects of the different treatments (zVAD, training, zVAD plus training) on neuronal survival were compared in each layer by one-way ANOVA (treatment effect), and between the two layers by two-way ANOVA (treatment effect and layer effect). During spontaneous odorant exploration, the habituation response (over the first four presentations of the habituation odorant) was analyzed between groups by two-way ANOVA (group effect and trial effect). The behavioral performances of mice in the olfactometer were compared between the different groups for each task, by two-way ANOVA (group effect and block/day effect) for repeated measures. Kolmogorov-Smirnov tests were used to compare cumulative distributions.

\section{Results}

\section{Local infusion of zVAD into the $\mathrm{OB}$ increases neuronal survival}

We first examined the prosurvival effect of the pancaspase inhibitor zVAD on newly generated neurons arriving in the adult $\mathrm{OB}$. Most neurons are eliminated within a critical time window after their arrival, and neurons surviving this initial period of cell elimination survive for several months or, perhaps, even permanently (Winner et al., 2002; Ninkovic et al., 2007; Mouret et al., 2008). We therefore focused our analysis on the period between 2 and 4 weeks after the initial generation of the cells, based on the results of previous studies by Yamaguchi and Mori (2005) and Mouret et al. (2008).

Newly generated neurons were labeled with BrdU, and animals received a continuous infusion of either $\mathrm{zVAD}$ or saline, directly into the $\mathrm{OB}$, between 16 and $30 \mathrm{~d}$ after BrdU injection (Fig. $1 A$ ). BrdU ${ }^{+}$cells were quantified in the different layers of the OB (Fig. $1 B, C$ ) to determine whether zVAD treatment enhanced their survival. Healthy $\mathrm{BrdU}^{+}$cells with large nuclei $(\sim 8$ $\mu \mathrm{m})$ were visible in all conditions, independently of zVAD treatment. Consistent with previous reports by Alonso et al. (2006) and Mouret et al. (2008), the density of new cells was higher in the GCL than in the GL, and significantly decreased between day 16 (D16) and D30 in saline-infused mice [controls; GCL (Fig. 1D), $t_{(9)}=17.65, p<0.0001$; GL (Fig. $1 E$ ), $t_{(9)}=5.72, p=0.0003$. During the same period, the elimination of cells was also observed in both layers in zVAD-infused animals [GCL (Fig. 1D), 
$t_{(9)}=4.05, p=0.0029$; GL (Fig. $\left.1 E\right), t_{(9)}=$ $3.45, p=0.0072$ ], but this decrease was less pronounced than in control animals [GCL (Fig. 1D), $t_{(10)}=14.11, p<$ 0.0001; GL (Fig. 1E), $t_{(10)}=3.46, p=$ 0.0062].

We expressed the efficiency of zVAD treatment by calculating the percentage of $\mathrm{BrdU}^{+}$cells for which survival was enhanced by zVAD between D16 and D30. This percentage was higher in the GCL $(73.6 \pm 4.2 \%)$ than in GL $(49.6 \pm 8.1 \%)$ (Fig. $1 F)\left(t_{(10)}=2.64 ; p=0.025\right)$. Thus, zVAD was more efficient in preventing the death of newly generated cells located in the GCL than of those located in the GL, suggesting that death pathways may differ as a function of neuronal subtype and/or location. As for control experiments, we checked that zVAD diffused evenly in the two OBs and, particularly, that its prosurvival effect was similar in the medial and lateral parts of the bulbs (supplemental Fig. S1 and data 1, available at www. jneurosci.org as supplemental material). The absence of gradient effects indicates that the differences observed between the GCL and GL were not attributable to drug diffusion. We also checked that hippocampal neurogenesis was not affected by bulbar zVAD infusion (supplemental Fig. S2 and data 2, available at www. jneurosci.org as supplemental material), further demonstrating the local action of zVAD into the bulb only.

We then investigated whether new cells had a neuronal phenotype by analyzing coexpression of BrdU with the neuronal marker NeuN (Fig. 1G). The percentage of $\mathrm{BrdU}^{+}$cells also labeled with NeuN was high at D30 ( $>90 \%$ in the GCL; $>50 \%$ in the GL), consistent with our previous findings (Alonso et al., 2006; Mouret et al., 2008). This colabeling was not affected by zVAD treatment (comparison between saline- and zVADinfused mice at D30: in the GCL, $t_{(10)}=$ $0.19, p=0.8500$; in the GL, $t_{(10)}=0.24$, $p=0.8131)$. Thus, the presence of the pancaspase inhibitor in cells did not alter the differentiation of neuroblasts into NeuN-expressing neurons. Bulbar zVAD infusion constitutes therefore an efficient mean for decreasing the cell death of bulbar interneurons.

\section{Bulbar zVAD infusion has no effect on} glomerular innervation

As for additional controls, we checked whether zVAD infusion could affect OSN projections to the OB. OSNs die by apoptosis at all stages in their life cycle and are continually replaced throughout life by the progeny of dividing basal cells located in the olfactory epithelium (Cowan and
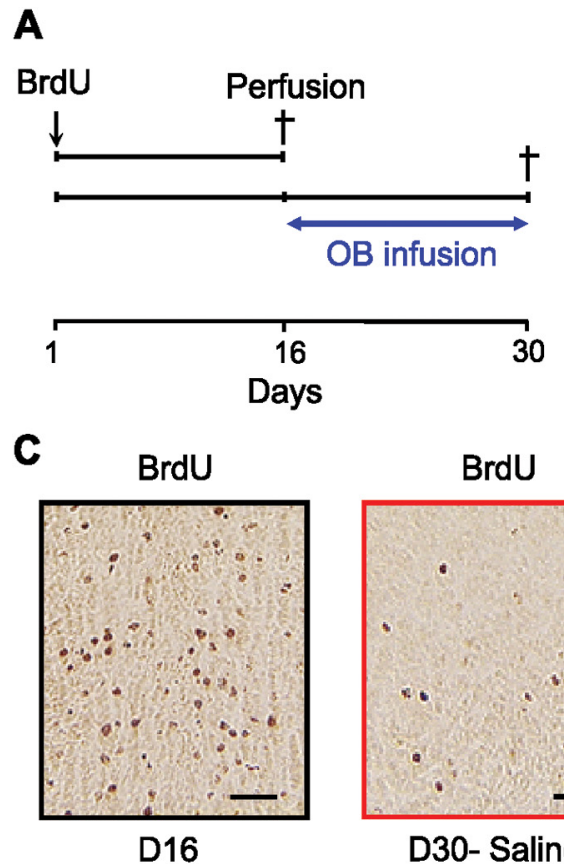

D
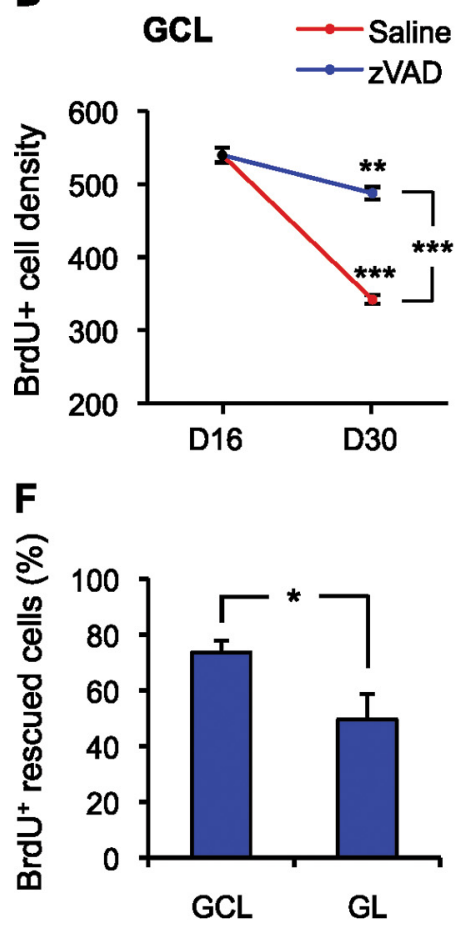

B

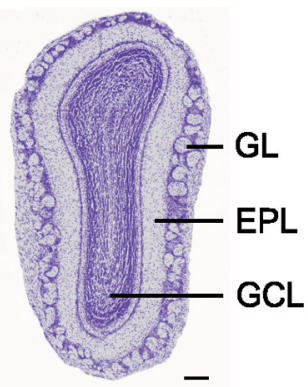

BrdU

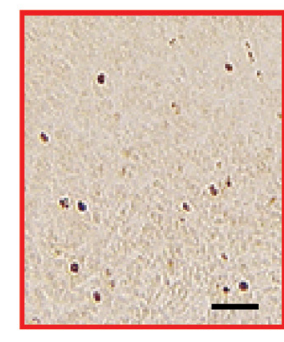

D30- Saline

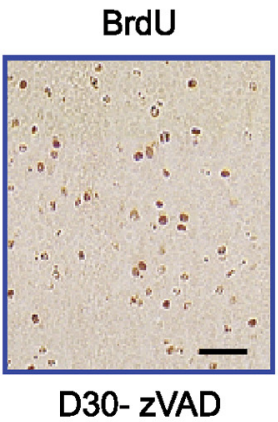

E

Figure 1. Bulbar zVAD infusion increases neuronal survival in the GCL and GL. $\boldsymbol{A}$, New cells were labeled with BrdU (day 1$)$, and their survival was evaluated $16 \mathrm{~d}(n=5)$ or $30 \mathrm{~d}(n=12)$ later. On day 15 , osmotic pumps diffusing saline $(n=6)$ or $\mathrm{ZVAD}(n=$ 6) for $15 \mathrm{~d}$ were implanted in the $O B$ of adult mice. $B, A$ coronal section of the left $O B$ stained with the nuclear dye DAPI to visualize the different layers. $C$, Representative images showing BrdU ${ }^{+}$cells in the $\mathrm{GCL}$ of animals 16 or $30 \mathrm{~d}$ after BrdU administration. At $30 \mathrm{~d}$, saline- and zVAD-infused animals are compared. $\boldsymbol{D}, \mathrm{BrdU}^{+}$cell density in the $\mathrm{GCL}$ before $(n=5)$ and after 2 weeks of saline $(n=6)$ or ZVAD $(n=6)$ bulbar infusion. ${ }^{* *} p<0.01 ;{ }^{* * *} p<0.001$. $\boldsymbol{E}$, BrdU ${ }^{+}$cell density in the GL before $(n=5)$ and after 2 weeks of saline $(n=6)$ or $\mathrm{ZAD}(n=6)$ infusion into the $0 \mathrm{~B} .{ }^{* *} p<0.01 ;{ }^{* * *} p<0.001$. F, Percentage of BrdU ${ }^{+}$cells for which death has been prevented between 16 and $30 \mathrm{~d}$ after BrdU administration, by bulbar zVAD infusion, in the GCL and GL. ${ }^{*} p<0.05$. G, Double-labeled cells in the GCL, 30 d after BrdU administration, showing the colocalization of BrdU (red) with NeuN (green). Scale bars: $\mathbf{C}, 75 \mu \mathrm{m} ; \mathbf{G}, 15 \mu \mathrm{m}$. Error bars indicate SEM. 
A

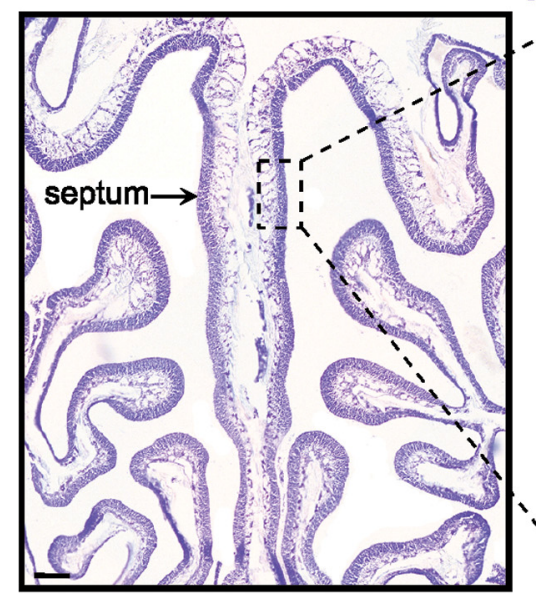

Cresyl Violet
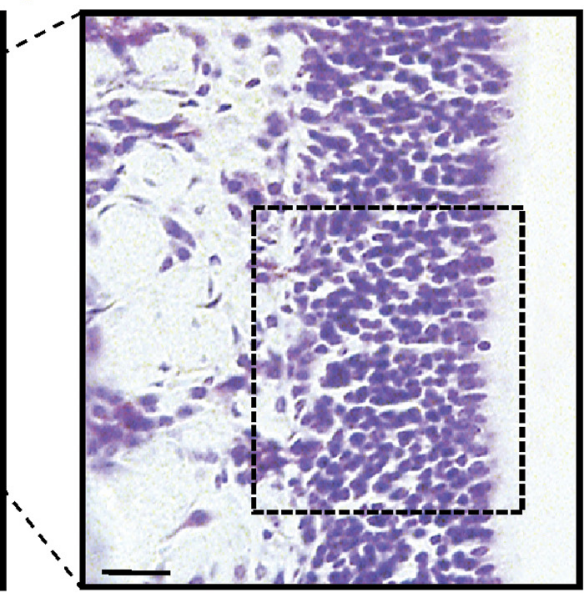

B

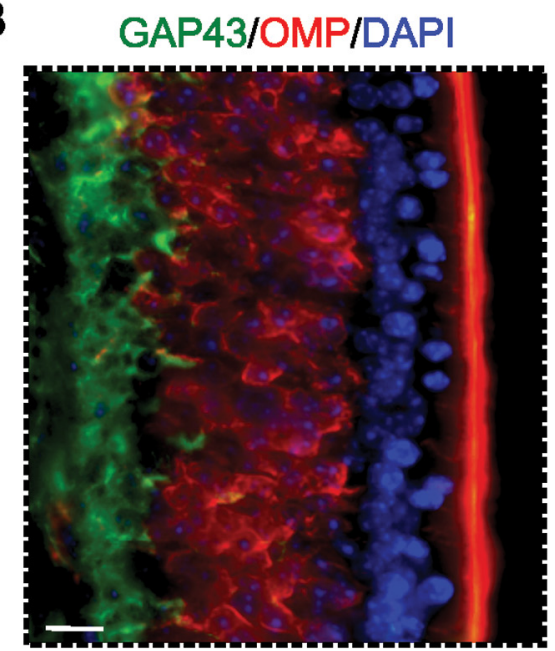

C

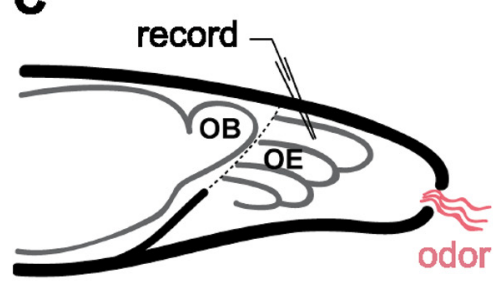

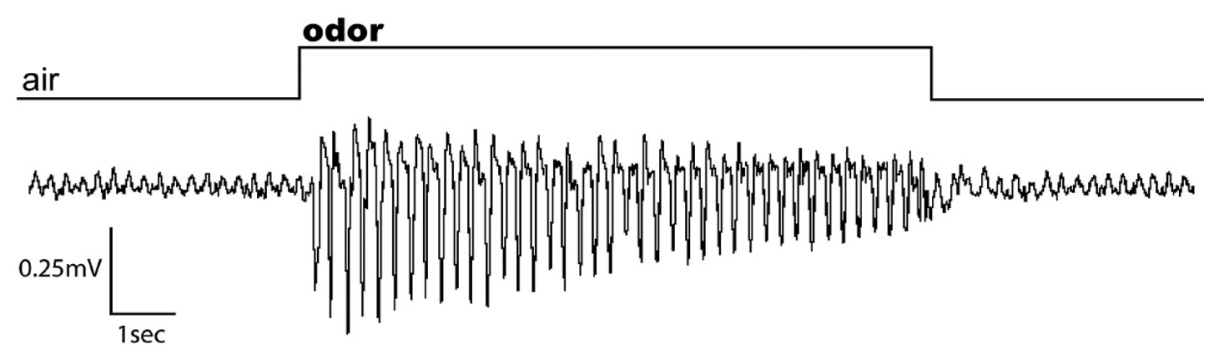

E

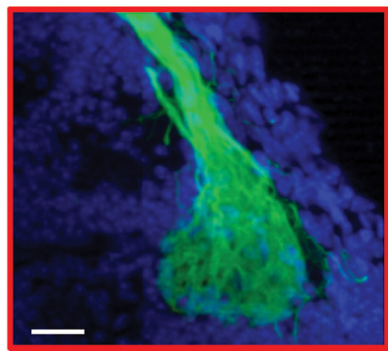

Saline
GFP/DAPI

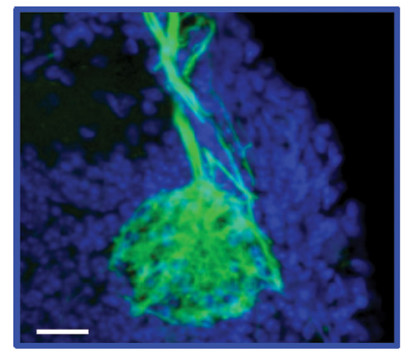

zVAD

Figure 2. Bulbar ZVAD delivery has no effect on glomerular innervation. $\boldsymbol{A}$, Coronal section of the OE stained with cresyl violet to visualize its organization (left) and a higher magnification of the OE septum (right). $\boldsymbol{B}$, Higher magnification of the OE septum (from boxed area in $\boldsymbol{A}$ ) stained with GAP43 (green)/OMP (red)/DAPI (blue). $\boldsymbol{C}$, EOGs were recorded through an electrode inserted in the OE (left). Example of an EOG response to odor presentation (right). $D, 0 M P$ (red)/DAPI (blue) staining in the GL after 2 weeks of saline (left) or zVAD (right) bulbar infusion. The boundary of the GL is outlined in white. $\boldsymbol{E}$, MOR23-GFP glomeruli of MOR23-GFP mice after saline (left) or zVAD (right) bulbar infusion. Cells are identified with DAPI staining (blue). Scale bars: $\boldsymbol{A}, 200 \mu \boldsymbol{m} ; \boldsymbol{A}$, inset, 25 $\mu \mathrm{m} ; \boldsymbol{B}, 10 \mu \mathrm{m} ; \boldsymbol{D}, \boldsymbol{E}, 25 \mu \mathrm{m}$.

treatment (Fig. 2A). No anatomical changes could be detected in the OE: neither the total thickness of the OE (Fig. $2 A$, inset) nor the thickness of the GAP $43^{+}$cell layer (immature neurons) and of the $\mathrm{OMP}^{+}$cell layer (mature neurons) were affected by infusing zVAD between the bulbs (Fig. $2 \mathrm{~B}$ ). We then checked whether the magnitude of the EOG response, which reflects the summed receptor potentials of OSNs, was sensitive to zVAD. As shown in Figure $2 C$, odor delivery in an anesthetized freely breathing mouse induced a series of slow negative potentials. They were synchronized with the respiratory rhythm and their amplitude decreased over the time as previously reported (Chaput and Chalansonnet, 1997). This typical pattern did not appear during pure air delivery. EOG response amplitude after odor stimulation was similar for zVAD-treated mice and controls $(0.49 \pm 0.06$ and $0.50 \pm 0.04 \mathrm{mV}$ for saline- and zVAD-infused mice, respectively; $\left.n=6 ; t_{(10)}=0.20 ; p=0.85\right)$. The amplitude ratio between odor and pure air responses was also measured and did not change with $\mathrm{zVAD}$ treatment $(84.6 \pm 14.0$ and $80.7 \pm 11.6$ for salineand $\mathrm{zVAD}$-infused animals, respectively; $n=6 ; t_{(10)}=0.22 ; p=$ 0.83 ). The absence of difference in the EOG strongly suggests that a similar number of activated OSNs participate to the odorevoked responses after $\mathrm{zVAD}$ treatment.

In the OB, we observed a strong OMP immunoreactivity in axon processes within the olfactory nerve layer and glomeruli (Fig. 2D). Yet no difference in the distribution and intensity of OMP staining was found between saline- and zVAD-treated animals (Fig. 2D) (mean OMP intensity within glomeruli, $48.8 \pm$ 4.5 and $46.2 \pm 4.8$ for saline- and zVAD-infused mice, respectively; $\left.n=6 ; t_{(10)}=0.41 ; p=0.69\right)$. This suggests intact OSN innervation in zVAD-treated mice. To confirm this result, we used a transgenic mouse strain in which cells expressing the odorant receptor MOR23 are tagged with tauGFP (Vassalli et al., 2002; 
Alonso et al., 2006). It allowed us to study the influence of $\mathrm{zVAD}$ infusion on the coalescence of OSN axons into glomeruli. Two weeks after zVAD treatment, all $\mathrm{GFP}^{+}$OSNs precisely converged toward two $\mathrm{GFP}^{+}$glomeruli per bulb. Those MOR23 glomeruli were normally positioned and showed unchanged size (Fig. $2 E)$. Thus, zVAD has no effect on the sorting of OSN axons into glomeruli in adult mice. We conclude that a 2 week OB infusion of $\mathrm{zVAD}$ does not affect OSN survival and glomerular innervation. Absence of zVAD effect on sensory neurons might be attributable to their low rate of turnover and/or to the fact that our method of drug delivery (dose and location) is not adapted to prevent OSN apoptosis. Together, our approach is specifically designed to examine the functional impact of cell death prevention in the adult $\mathrm{OB}$.

\section{zVAD effect differs as a function of neuronal subtype and sensory experience}

We investigated whether $\mathrm{zVAD}$ effect on neuronal survival occurred by mechanisms similar to those operating during learning. We thus analyzed the efficacy of zVAD treatment during olfactory learning. Our previous studies have shown that olfactory learning modulates neuronal survival, through an unknown mechanism (Alonso et al., 2006; Mouret et al., 2008). We hypothesized that zVAD infusion might mimic a learning period, at least when considering changes in neuronal survival. We compared zVAD treatment and learning by labeling new neurons with BrdU and continuously infusing the $\mathrm{OB}$ with $\mathrm{zVAD}$ or saline, between days 16 and 30 after BrdU injection. One-half of the population of mice in each group underwent intensive odor discrimination training with multiple odorants, and $\mathrm{BrdU}^{+}$cell density was counted in the GCL and the GL (Fig. $3 A$ ). As described above (Fig. $1 D, E$ ), BrdU ${ }^{+}$cell density strongly declined in both layers between D16 and D30 in naive animals (Fig. $3 B, C)$, with a more marked effect in animals infused with saline than in those treated with $\mathrm{zVAD}$. As expected, the survival of newly generated cells in both layers increased with learning in saline-infused animals [GCL (Fig. $3 B), t_{(13)}=8.19$, $p<0.0001$; GL (Fig. $3 C$ ), $t_{(13)}=2.32, p=0.0380$ ]. In the GCL, the density of new cells was also higher in trained zVADinfused animals than in naive animals (Fig. $3 B)\left(t_{(13)}=2.79\right.$; $p=0.0155)$. In contrast, $\mathrm{BrdU}^{+}$cell density was similar in the GL of zVAD-treated mice, regardless of their experience status (Fig. $3 C)\left(t_{(13)}=0.94 ; p=0.3644\right)$.

We normalized the data to facilitate comparisons between the effects of the different treatments ( $\mathrm{zVAD}$ alone, training alone, or $\mathrm{zVAD}$ plus training) on neuronal survival (Fig. $3 D$ ). In the GCL, the treatments had different effects on adult neurogenesis (treatment effect in the GCL, $\left.F_{(2,20)}=19.95 ; p<0.0001\right)$. zVAD was more efficient at preventing neuronal death $(71.7 \pm 4.8 \%$ of death prevention) than training alone $\left(49.4 \pm 4.4 \% ; t_{(13)}=3.41\right.$; $p=0.0047)$. Interestingly, the effects of the two treatments were

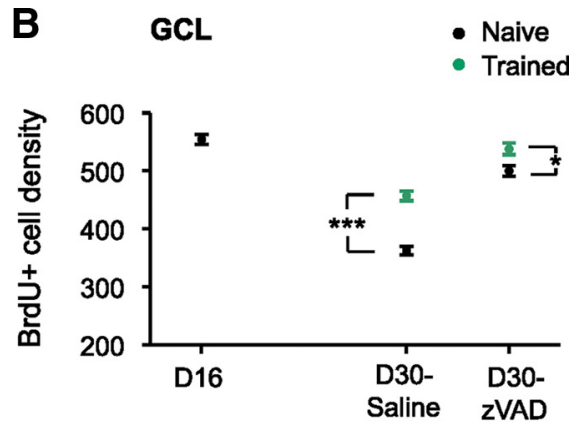

D
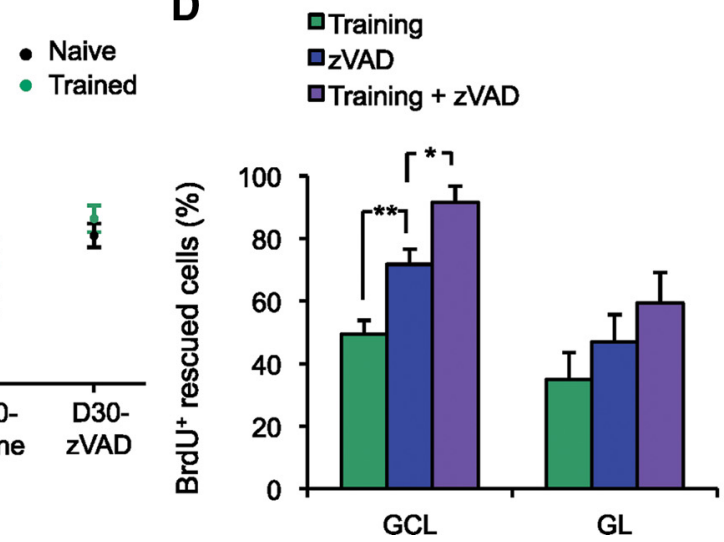

GCL

GL

Figure 3. Different effects of learning and $Z \mathrm{VAD}$ on new neuron survival. $A$, New cells were labeled with $\operatorname{BrdU}$ (day 1 ), and their survival was evaluated $16 \mathrm{~d}(n=5)$ or $30 \mathrm{~d}(n=30)$ later. On day 15 , osmotic pumps diffusing saline $(n=15)$ or $\mathrm{ZVAD}(n=15)$ $15 \mathrm{~d}$ were implanted in the $\mathrm{OB}$ of adult mice. One-half of the population of mice in the saline group $(n=8)$ and in the ZVAD group $(n=8)$ underwent olfactory learning when $\mathrm{BrdU}^{+}$cells were between 16 and $30 \mathrm{~d}$ old. $\boldsymbol{B}, \boldsymbol{C}$, BrdU ${ }^{+}$cell density before which death has been prevented in the GCL and GL, between 16 and $30 \mathrm{~d}$ after BrdU administration, by olfactory learning and/or by bulbar ZVAD infusion. ${ }^{*} p<0.05 ;{ }^{* *} p<0.01$. Error bars indicate SEM.

additive, as we observed an almost total blockade of neuronal death in trained animals treated with zVAD $(91.5 \pm 5.1 \%)$. The proportion of cells for which death had been prevented by the two treatments used together was significantly higher than the one observed after zVAD treatment alone $\left(t_{(13)}=2.78 ; p=\right.$ $0.0156)$. In contrast, all treatments had smaller effects on neuronal survival in the GL than in the GCL (layer effect, $F_{(1,40)}=$ 13.94, $p=0.0006$; treatment effect, $F_{(2,40)}=9.49, p=0.0004$; interaction layer by treatment, $\left.F_{(2,40)}=0.68, p=0.5142\right)$. Furthermore, the proportion of cells for which death had been prevented in the GL did not differ significantly between treatments (training, $34.9 \pm 10.9 \%$; zVAD, $46.9 \pm 8.8 \%$; zVAD plus training, $59.3 \pm 9.7 \%$; treatment effect in the GL, $F_{(2,20)}=1.58, p=$ $0.2307)$. The combination of $\mathrm{zVAD}$ and training increased survival $\sim 20 \%$ more than training alone, but this difference was not significant $\left(t_{(14)}=1.68 ; p=0.116\right) . z V A D$ and training effects on cell survival in the GL were therefore not synergistic. We conclude that the interneurons located in different layers are not equally sensitive to training and to antiapoptotic factors: The survival of new granule cells is more adaptable than that of new periglomerular cells.

\section{Bulbar zVAD infusion increases spontaneous olfactory investigation}

We evaluated the impact of cell death blockade on behavioral functions using a spontaneous olfactory discrimination test. As shown before, this task is related to adult neurogenesis (Gheusi et al., 2000; Mechawar et al., 2004), so we hypothesized that disturb- 


\section{A

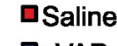 \\ 口ZVAD}
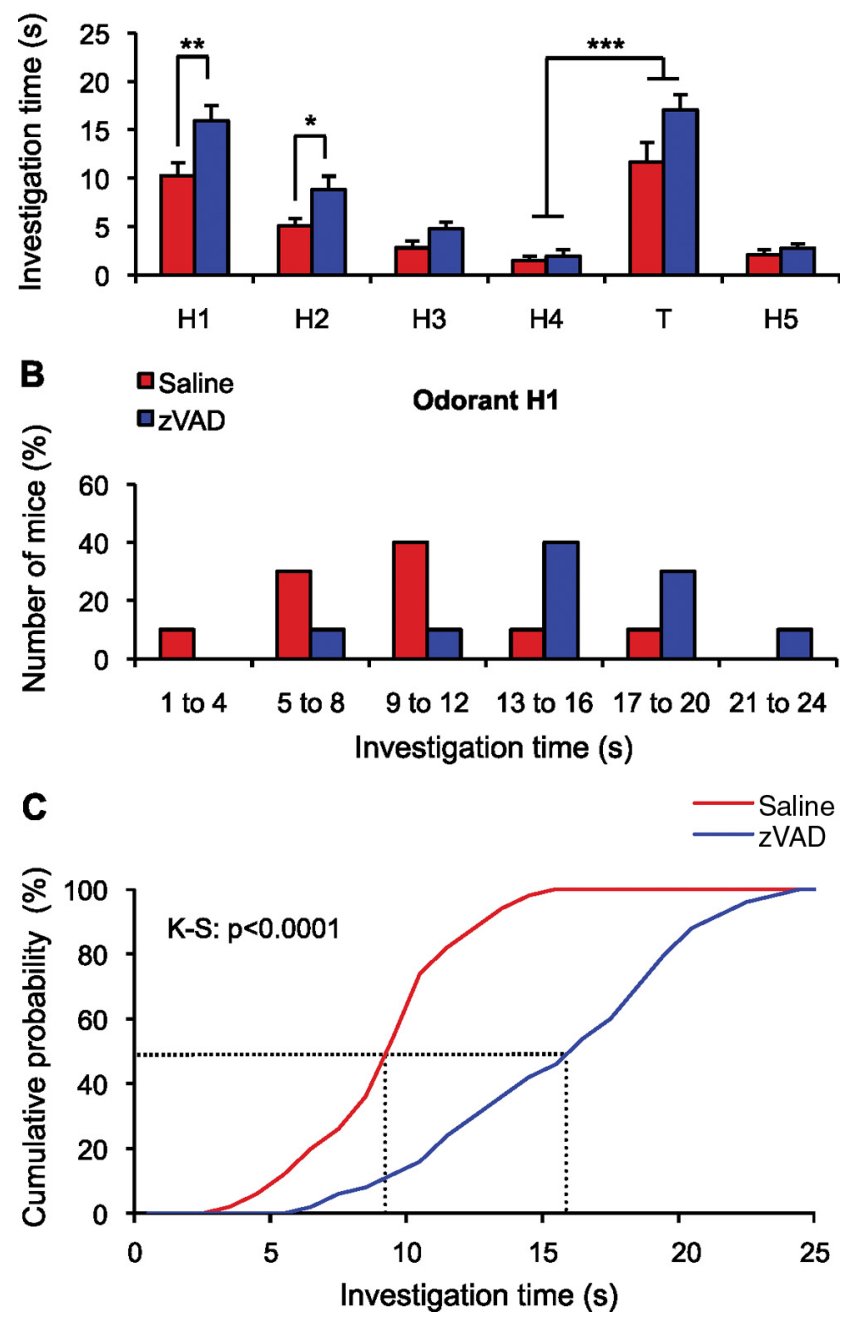

Figure 4. ZVAD-infused mice spend more time spontaneously investigating new odorants than controls but discriminate odorants similarly. $\boldsymbol{A}$, Habituation profiles for saline-infused $(n=10)$ and $z V A D$-infused $(n=10)$ mice, showing a clear reduction in investigation time across four repeated presentations of a habituation odorant $(\mathrm{H})$ and a significant increase in the investigation time for a dissimilar test odorant $(\mathrm{T})$, presented before the last exposure to the habituation odorant (H5). ${ }^{*} p<0.05 ;{ }^{* *} p \leq 0.01 ;{ }^{* * *} p<0.001$. Error bars indicate SEM. $\boldsymbol{B}$, Distribution of the investigation times for the first presentation of the habituation odorant (H1) (see $\boldsymbol{A}$ ) for saline-infused $(n=10)$ and ZVAD-infused $(n=10)$ mice. $\boldsymbol{C}$, Cumulative distribution of the investigation times for the first presentation of different odorants for salineinfused ( $n=10$ ) and zVAD-infused $(n=10)$ mice. The dotted lines represent the mean values for the two groups of mice.

ing the rate of neuronal turnover might lead to substantial functional impairment. Mice performing the spontaneous olfactory discrimination task received continuous $\mathrm{OB}$ infusions of either zVAD, or saline, and were tested between 10 and $15 \mathrm{~d}$ after the start of infusion. Mice were repeatedly presented with a single habituation odorant $(\mathrm{H})$ over four consecutive trials. Their interest in the odorant was evaluated by measuring the investigation time. Interest clearly decreased over the trials (from $\mathrm{H} 1$ to $\mathrm{H} 4$ ), through a process called habituation (Gheusi et al., 2000; Linster et al., 2002) (Fig. 4A) [time effect (H1 to H4), $F_{(3,72)}=49.23, p<$ 0.0001 ; group effect ( $\mathrm{zVAD}$ or saline), $F_{(1,72)}=17.40, p<0.0001$; interaction time by group, $\left.F_{(3,72)}=2.51, p=0.0651\right]$. Saline- and zVAD-infused mice displayed similar patterns of habituation to the odorants (Fig. 4A) (comparison $\mathrm{H} 1 / \mathrm{H} 4$ : for saline-infused mice, $t_{(18)}=6.71, p<0.0001$; for $\mathrm{zVAD}$-infused mice, $t_{(18)}=$ $8.39, p<0.0001)$. A test odorant $(\mathrm{T})$ was then presented and the ability of the mice to discriminate between the test odorant and the habituation odorant was assessed. A significant increase in investigation time corresponded to spontaneous discrimination between odorant stimuli. A final presentation of the habituation odorant (H5) was used to confirm that mice continued to recognize the habituation odorant. Regardless of treatment, mice succeeded in discriminating spontaneously between dissimilar odorants (Fig. 4A) (comparison H4/T: for saline-infused mice, $t_{(18)}=5.23, p<0.0001$; for $\mathrm{zVAD}$-infused mice, $t_{(18)}=8.84, p<$ 0.0001 ), but failed to discriminate between similar odorants (supplemental Table 1, available at www.jneurosci.org as supplemental material). Thus, zVAD treatment did not change spontaneous discrimination performance. Interestingly, Figure $4 A$ also shows that zVAD-treated mice spent significantly more time than controls investigating the habituation odorant, during its first and second presentations $\left(t_{(18)}=2.88, p=0.0100\right.$, and $t_{(18)}=$ 2.32, $p=0.032$, respectively). The distribution of investigation times for mice exposed to the habituation odorant for the first time (e.g., H1) provides a more precise illustration of the impact of zVAD on spontaneous exploration (Fig. $4 B$ ). When cell death level was reduced, $\mathrm{H} 1$ exploration time was longer $(15.8 \pm 0.6 \mathrm{~s})$ than that in controls $(9.4 \pm 0.4 \mathrm{~s} ; p<0.0001$ ) (Fig. $4 C)$. We checked that this effect was restricted to new odorants and not to new stimuli per se (data not shown). Thus, disturbing the degree of cell elimination in the $\mathrm{OB}$ increases the spontaneous investigation of new olfactory stimuli, but not the rate at which mice become habituated or dishabituated to repeated and new odorants, respectively.

\section{Blocking cell elimination has no effect on olfactory learning and memory}

After exploring spontaneous olfactory behavior, we assessed the effects of blocking cell death on rewarded discrimination tasks. During these experiments, the $\mathrm{OB}$ was infused continuously with either zVAD or saline. Mice underwent training in a go/no-go odor discrimination task, in which a correct response to one odorant $(S+)$ was rewarded by the delivery of water (Fig. $5 A$ ). Each time a new pair of odorants was presented, mice initially had a performance similar to that expected on the basis of chance (i.e., $50 \%$ of correct responses). Performance gradually improved, reaching the defined performance criterion (i.e., $>85 \%$ of correct responses) in 1 or $2 \mathrm{~d}$ (Fig. $5 \mathrm{~B}$ ), depending on the experience of the mouse and the difficulty of the task. Regardless of treatment, for all pairs of odorants tested (see Materials and Methods), mice learned to discriminate between the two stimuli at equivalent rates, reaching the same percentages of correct responses. A task previously considered difficult (Linster et al., 2002) is presented in Figure $5 B$. The performances of saline- and $z V A D$-treated mice were indistinguishable over time (T1: group effect, $F_{(1,126)}=$ $1.13, p=0.3047$; block effect, $F_{(9,126)}=23.80, p<0.0001$; interaction block by group, $F_{(9,126)}=0.16, p=0.9973$; T2: group effect, $F_{(1,126)}=0.03, p=0.8738$; block effect, $F_{(9,126)}=37.08$, $p<0.0001$; interaction block by group, $F_{(9,126)}=0.60, p=$ $0.7973)$.

We used mixtures of two enantiomer compounds to increase the difficulty of the task and to challenge animals in a task evolving over the course of a week. The concentration of one compound was progressively decreased over successive sessions, making the stimuli more similar over time (Fig. 5C). This made it possible to evaluate the discrimination threshold for one particular odorant: $(-)$-carvone. All mice succeeded in the task until 

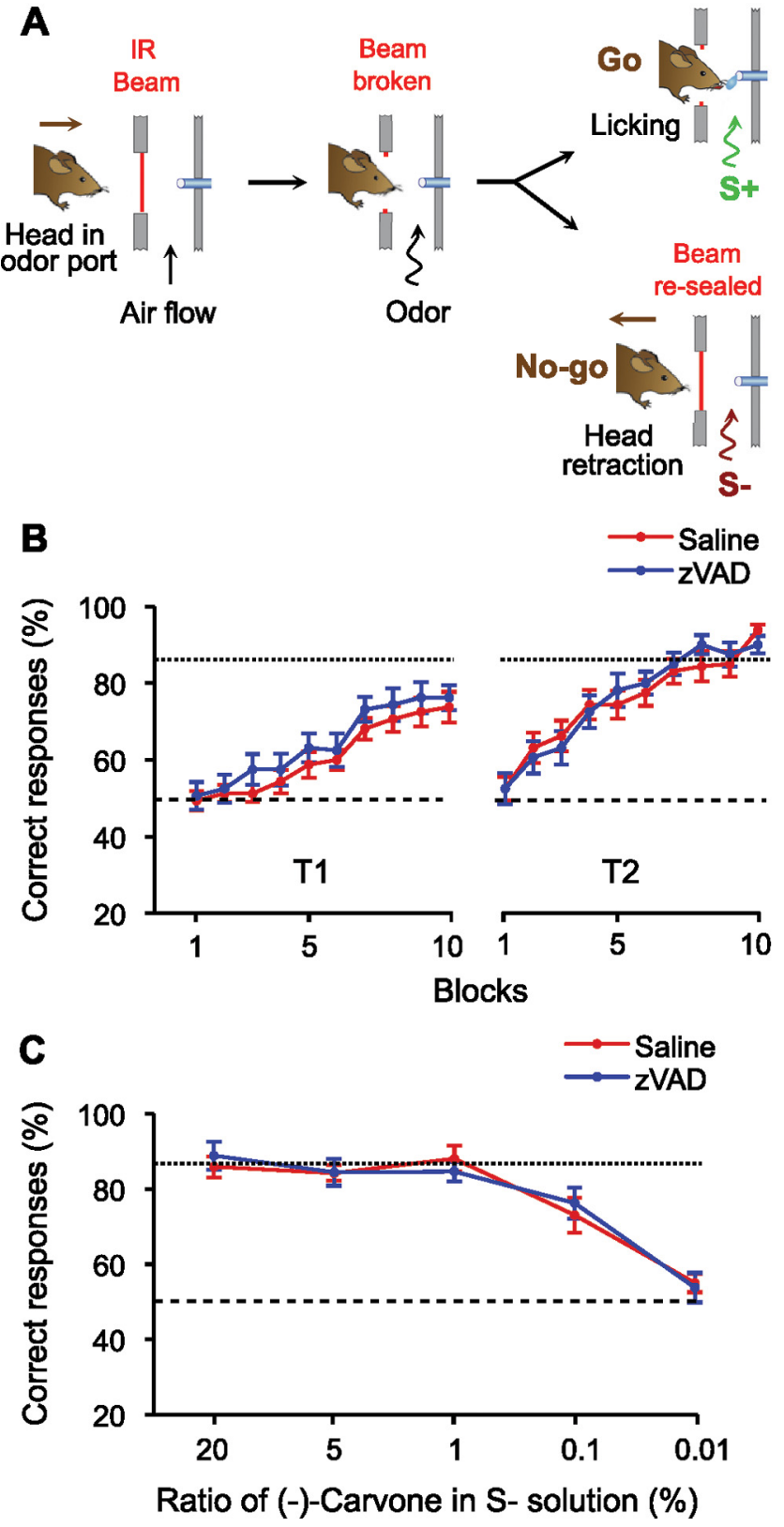

Figure 5. Blocking cell death has no effect on olfactory discrimination task performances. $A$, Presentation of the go/no-go procedure. The mouse breaks the light beam across the odor port, which initiates a trial. An odor is then presented during $2 \mathrm{~s}$. Licking in response to a rewarded odor $(S+)$ triggers water delivery $(\mathrm{g} 0)$. In response to an unrewarded odor $(S-)$, the trained animal retracts its head (no-go). $\boldsymbol{B}$, Mean percentage of correct responses in each block of $2 \mathrm{~d}$ (T1 and T2) of training for saline-infused $(n=8)$ and ZVAD-infused $(n=8)$ mice. $S+$ is $(+)$-limonene and $S-$ is $(-)$-limonene. $C$, Mean percentage of correct responses for each day of training for saline-infused $(n=7)$ and zVAD-infused $(n=7)$ mice. $S+$ is $(+)$-carvone and $\mathrm{S}-$ is a mix of $(+)$-carvone and $(-)$-carvone. Each day the ratio of $(-)$-carvone in the $S-$ solution is decreased (from 20 to $0.01 \%$ ). The dashed lines represent chance level (50\%), and the dotted lines represent the performance criterion (85\%). Error bars indicate SEM.

the minority compound accounted for only $1 \%$ of the mixture. The performance gradually decreased thereafter, and, at a proportion of $0.01 \%$, animals were unable to discriminate between odorant stimuli. Thresholds and profiles were identical for both groups of mice (Fig. 5C) (group effect, $F_{(1,48)}=0.03, p=0.8583$; day effect, $F_{(4,48)}=31.13, p<0.0001$; interaction day by group, $\left.F_{(4,48)}=0.32, p=0.8620\right)$. Thus, we conclude that blocking neuronal death has no effect on olfactory discrimination performance, at least when evaluated through an operant task.
Increasing neuronal survival is correlated with stronger olfactory memory (Rochefort et al., 2002). We therefore assessed the memory of treated mice further. Saline- and zVAD-infused mice learned to discriminate between two odorants in the go/no-go paradigm (Fig. $6 \mathrm{Ai}$ ). Their memory, not only of the two odorants but also of their value (reinforced or non-reinforced), was then tested. Mice underwent a first memory test $24 \mathrm{~h}$ after learning the task and a second test $4 \mathrm{~d}$ later, after two sessions of interference learning. The interference task aimed to make memorization more difficult and challenged the behavioral flexibility of the mice. All mice remembered correctly the task they had learned, even after a period of interference learning (Fig. 6 Aii) (comparison of saline- and zVAD-infused mice, $t_{(14)}=0.53, p=0.605$ for the first memory test; $t_{(14)}=0.38, p=0.719$ for the second memory test). No difference in the pattern of change in the performance of the mice or in their degree of success was observed between the two groups (group effect, $F_{(1,56)}=0.003, p=0.959$; day effect, $F_{(4,56)}=33.30, p<0.0001$; interaction day by group, $\left.F_{(4,56)}=0.72, p=0.583\right)$. Blocking the natural phenomenon of cell elimination therefore has no obvious effect on the short-term memorization of odors.

For experiments designed to study long-term memory, mice first learned to discriminate between two enantiomer compounds, this task being consolidated over $4 \mathrm{~d}$ (Fig. $6 \mathrm{Bi}$ ), and memory was tested 1 month later. Both groups not only learned the task and achieved the performance criterion similarly (group effect, $F_{(1,24)}=0.93, p=0.363$; day effect, $F_{(3,24)}=$ $21.10, p<0.0001$; interaction day by group, $F_{(3,24)}=0.31, p=$ 0.820 ), but they also remembered the task (Fig. 6 Bii) (comparison of saline- and zVAD-infused mice for the memory test, $t_{(8)}=$ $0.48, p=0.643$ ). Collectively, these data suggest that bulbar cell death is not required for odor discrimination and memory.

\section{Blocking cell death slows olfactory reaction time}

Finally, we assessed the reaction time of zVAD-treated mice in an olfactory discrimination task. We hypothesized that the processing of olfactory stimuli might be affected since zVAD-treated mice displayed longer periods of olfactory investigation during spontaneous exploration. Each odor is presented for $2 \mathrm{~s}$ by the olfactometer, and mice must continually lick the water delivery tube located in the odorant port to obtain the reward in response to $\mathrm{S}+$ stimuli. In contrast, when recognizing $\mathrm{S}-$ stimuli, trained animals stop licking and retract their heads (Fig. 7A). During the first few centiseconds of odorant presentation, the probability of licking is inevitably random, as animals cannot yet recognize the stimulus presented. After this short lag phase, licking patterns in response to $\mathrm{S}+$ or $\mathrm{S}-$ evolve differently, indicating discrimination between the two stimuli. Analysis of changes in the probability of licking over the course of odor presentation is thus a reliable method for assessing discrimination time. For a mouse performing a task correctly, the discrimination time corresponds to the time point at which a stable, significant difference between the licking probabilities for $\mathrm{S}+$ and $\mathrm{S}-$ appears (Fig. $7 A$ ). In contrast, licking frequencies do not change over time if mice fail to recognize the values of the two odorants presented or if they are unable to discriminate between them (Fig. $7 B$ ).

We used this method to compare the discrimination times of saline- and zVAD-infused mice when reaching the performance criterion (see Materials and Methods). OB infusion was initiated at least $5 \mathrm{~d}$ before mice began their training. Blocking cell death increased the discrimination time (Fig. 7C). The mean discrimination time for control mice was $440.0 \pm 29.1 \mathrm{~ms}$, whereas zVAD-treated animals made their licking decision in $550.6 \pm$ 

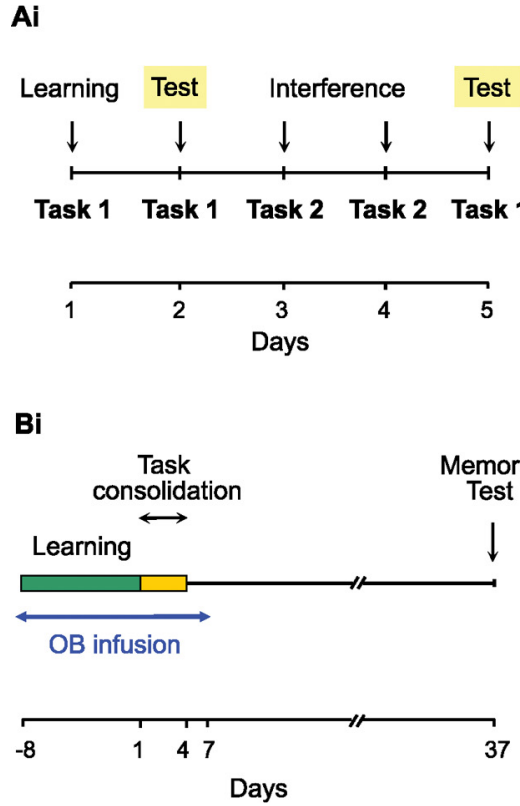

Aii
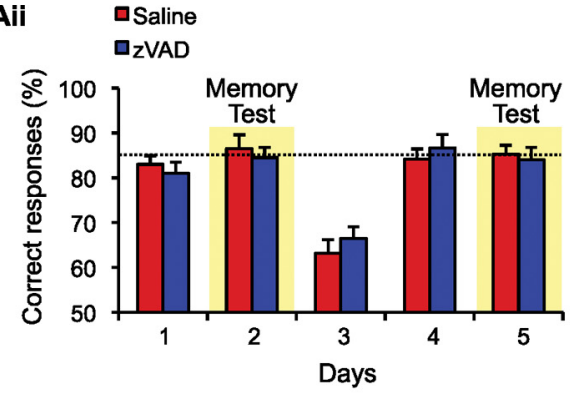

Bii

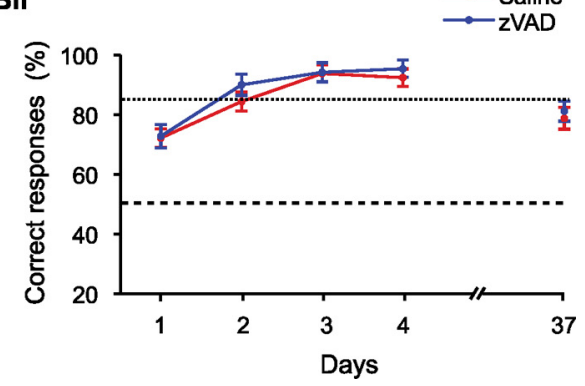

Figure 6. Blocking cell death has no effect on short-term and long-term olfactory memories. Ai, Saline-infused $(n=8)$ and zVAD-infused ( $n=8$ ) mice learned to discriminate between two odorants (task 1 on day 1 ), and the memory of this task was tested $24 \mathrm{~h}$ (day 2) and $96 \mathrm{~h}$ (day 5) later. Between the two memory tests, mice underwent interference learning (task 2 on days 3 and 4 ). Aii, Mean percentage of correct responses for each day of training/testing for saline-infused $(n=8)$ and zVAD-infused $(n=8)$ mice. Bi, Eight days before testing, osmotic pumps diffusing saline $(n=5)$ or $\operatorname{ZVAD}(n=5)$ for $15 \mathrm{~d}$ were implanted in the $0 \mathrm{Bs}$ of mice. Mice underwent $9 \mathrm{~d}$ of different olfactory discrimination tasks before learning to discriminate between $(+)$-carvone and (-)-carvone, and this task was consolidated over 4 consecutive days (days 1-4). One month later (day 37), the long-term memory of the mice was tested. Bii, Mean percentage of correct responses for each day of training and for the memory test for salineinfused $(n=5)$ and zVAD-infused $(n=5)$ mice. The dashed lines represent chance level $(50 \%)$, and the dotted lines represent the performance criterion (85\%). Error bars indicate SEM.

$27.3 \mathrm{~ms}\left(n=10 ; t_{(18)}=2.77 ; p=0.0126\right)($ Fig. $7 D, p<0.0001)$. However, the initial licking probabilities of the two groups of mice were similar, and the change in licking patterns in response to $\mathrm{S}+$ and $\mathrm{S}-$ after the discrimination time were independent of treatment (data not shown). Thus, zVAD infusion influenced the discrimination time but had no effect on any other licking behavior parameter. We controlled for the putative influence of $\mathrm{zVAD}$ infusion on the motivation or alertness of the animal in the olfactometer by measuring the duration of the daily behavioral olfactory discrimination sessions. Saline-treated animals spent $37.9 \pm 2.7$ min each day in the olfactometer performing the task (10 blocks). This duration was comparable for $\mathrm{zVAD}$-treated animals (39.8 $\pm 3.1 \mathrm{~min} ; t_{(18)}=0.46 ; p=0.6511$ ). Thus, bulbar cell death plays a specific role in adjusting the time between the presentation of olfactory stimuli and the subsequent behavioral response (i.e., lick or refrain from licking).

\section{Discussion}

There is mounting evidence supporting a functional impact of adding new neurons to mature circuits (Abrous et al., 2005; Doetsch and Hen, 2005; Aimone et al., 2006; Kempermann, 2008; Zhao et al., 2008). It remains yet unclear whether the elimination of new neurons represents a complementary strategy for the adjustment of circuit functioning. Here, we investigated this aspect and showed that spontaneous olfactory exploration and a rapid reaction time both required the continuous elimination of new neurons. This study provides the first demonstration of a role for programmed cell death over and above a simple homeostatic mechanism adjusting the number of elements in a given adult circuit.

\section{Functional significance of adult neurogenesis and death decision}

The survival rate of newborn neurons differs substantially across ages. Whereas almost the entire population of earlygenerated postnatal granule cells survives until adulthood (Lemasson et al., 2005), only a subset of newborn neurons survives during adulthood (Winner et al., 2002). Early-born granule cells showing low cell turnover appear as building blocks for the $\mathrm{OB}$ circuitry and may be required for vital and long-lasting olfactory behaviors (Lemasson et al., 2005). In contrast, granule cells generated during adulthood, and endowed with short-term survival, might rather participate in a fine-tuning of olfactory abilities (Gheusi et al., 2000; Rochefort et al., 2002; Lledo and Gheusi, 2003). The regulation of their survival/maturation by sensory experience within a critical time window supports this assumption (Petreanu and Alvarez-Buylla, 2002; Yamaguchi and Mori, 2005; Mouret et al., 2008). Adult-generated neurons surviving this initial period of massive apoptosis then survive for several months or, perhaps, even permanently (Winner et al., 2002). Thus, the OB circuits contain both a small cohort of plastic neurons, constantly renewed, and a large number of neurons generated at earlier stages that are not turned over (Ninkovic et al., 2007). By blocking the death normally occurring between 15 and $30 \mathrm{~d}$ after cell birth, zVAD infusion in adult mice prevents the selection/elimination processes of adult-generated neurons. It remains to be elucidated how the survival/death decision is made in a single neuron that initially contacts multiple partners. So far, only a small number of factors have been shown to influence the survival rates of new neurons. We have previously shown that mice lacking functional nicotinic acetylcholine receptors have higher survival rates for new granule cells, but not for new periglomerular neurons (Mechawar et al., 2004). Other studies have shown that the survival of newly generated OB granule cells depends on sensory input (Corotto et al., 1994; Petreanu and Alvarez-Buylla, 2002; Rochefort et al., 2002; Miwa and Storm, 2005; Yamaguchi and Mori, 2005; Mouret et al., 2008). The higher levels of cell survival, seen after the sensory input activity has been enhanced, could be mediated by the antiapoptotic protein Bcl-2. Odor presentation increases bulbar Bcl-2 levels (Miwa and Storm, 2005), and mice overproducing this protein have higher levels of new hippocampal neuron survival (Kuhn et al., 2005). In contrast, Bax is critical for the elimination of OB interneurons (Kim et al., 2007).

The demonstration that sensory experience is an appropriate stimulus, at least for some newly generated neurons, imposes temporal constraints on the question of the function of new neurons. In adults, the experience-induced regulation of neurogenesis may have two purposes: acute recruitment of the currently available immature neurons, dependent on a critical time window (Magavi et al., 2005; Yamaguchi and Mori, 2005; Alonso et al., 2006; Mouret et al., 2008), and the stimulation of mechanisms for increasing the pool of such recruitable cells over longer time- 
scales. During neuronal development in the adult $\mathrm{OB}$, the fate of new neurons may be decided very early on, before functional integration. Indeed, new neurons receive inputs from the circuit into which they integrate, much before they are able to make any output (Whitman and Greer, 2007; Kelsch et al., 2008). In addition to this process, there seems to be a second late refinement that is actually dependent on the full functional integration of the new neurons, requiring the hallmark of synaptic contacts between mature neurons (Livneh et al., 2009). The mechanisms underlying this late fine-tuning and their specific and respective contributions to granule cell and periglomerular cell selection remain unknown.

In this study, we found that experienceinduced increase in cell survival acted synergistically with zVAD action for neurons in the GCL but not for those in the GL. We conclude that the survival of adultgenerated granule cells can be modified more strongly than that of periglomerular cells. Additional studies are now required to determine the reasons for the major differences in the life span of the new neurons in different circuitries, and to determine why sensory experience increased the survival of a larger number of granule cells, but not of periglomerular neurons, in $\mathrm{zVAD}$-treated mice. It will also be important to determine whether adult neuronal replacement acts simply to keep networks functionally young, by randomly removing a certain proportion of neurons and adding new neurons continuously, or whether the eliminated cells had failed to mature fully, did not reach their correct location, or had established aberrant connections. If cells are eliminated for a particular reason, then neuronal replacement should be considered as a complex tuning of neuronal circuits, rather than as a means of simply rejuvenating existing networks.

\section{Spontaneous and reinforced olfactory discriminations require the death of new neurons}

We investigated whether the elimination of new neurons affected olfactory information processing, using two different behavioral protocols. The habituation/dishabituation paradigm focuses on odor perception, whereas the differential reinforcement test assesses odor discrimination (Rubin and Katz, 2001). We showed that odorant detection, discrimination ability, and odor memory were unaffected by blocking the elimination of new neurons. However, although mice were able to recognize odorants, with or without reinforcement, mice lacking the ability to eliminate cells took longer to investigate new odorants during spontaneous exploration and to discriminate between odorants in the olfactometer. A previous study in which cell death was genetically blocked did not
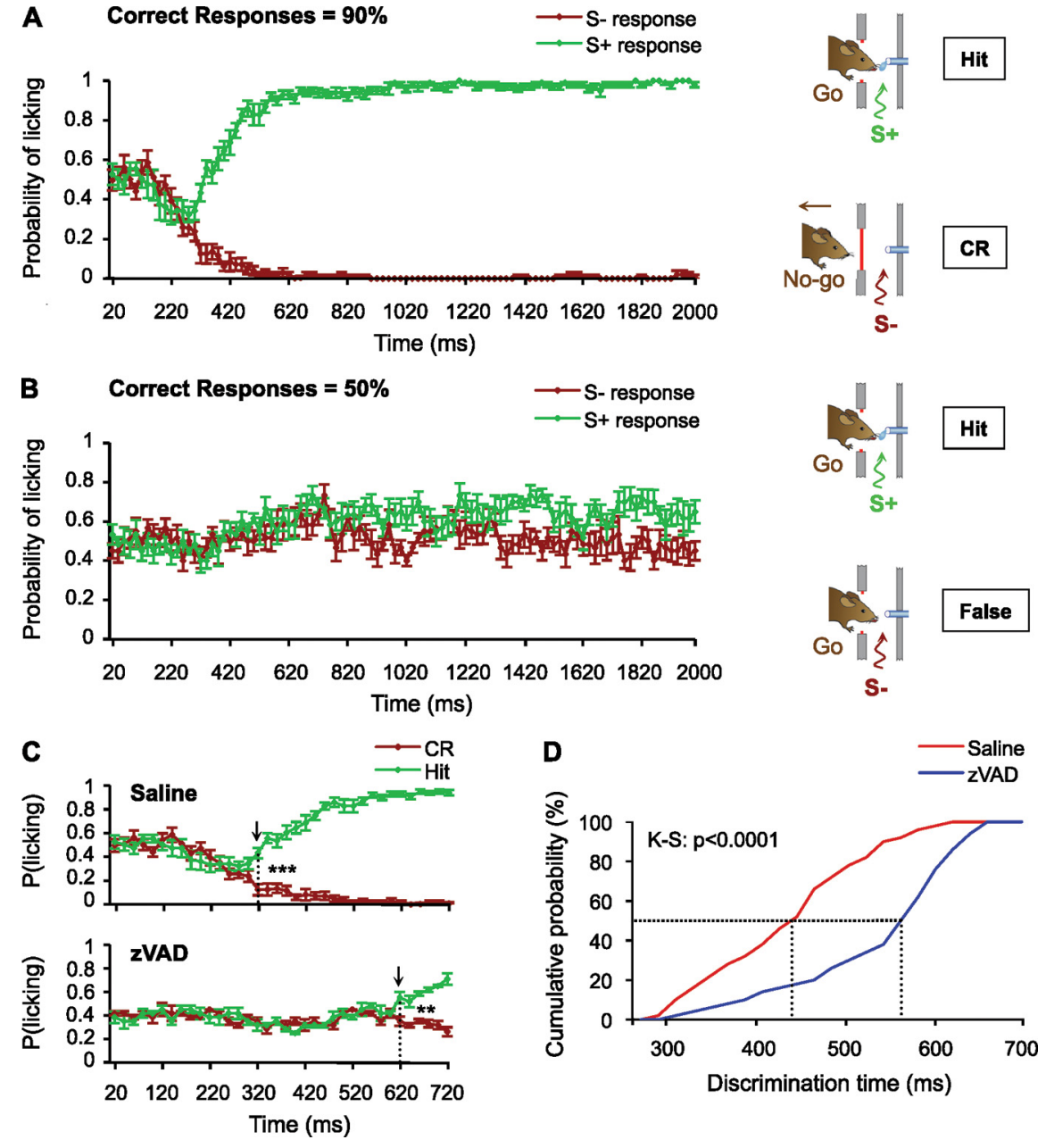

Figure 7. Blocking cell death increases the discrimination time of mice performing olfactory discrimination tasks. $A$, Probability performance criterion ( $90 \%$ correct responses). Mice increase their licking rates when recognizing $S+$ (hit), to get the water reward, and stop licking to retract their head when recognizing $S-(C R$, correct rejection). $B$, Probability of licking during the 2 for SEM. $\boldsymbol{D}$, Cumulative distribution of the discrimination times for saline-infused $(n=10)$ and $\mathrm{VVAD}$-infused $(n=10)$ mice. The dotted lines represent the mean discrimination times for the two groups of mice.

investigate these parameters (Kim et al., 2007). A modeling approach based on the activity-dependent survival of new granule cells has suggested that new neurons adjust the tuning of bulbar activity to improve discrimination (Cecchi et al., 2001). The present results and those of others (Gheusi et al., 2000; Enwere et al., 2004) support this assumption.

Discrimination times estimated from psychophysical analysis Neuronal computations in the OB occur within the first few hundred milliseconds of an odorant response. The pattern segregation of sensory inputs may be observed within $\sim 400 \mathrm{~ms}$ (Friedrich et al., 2004). As odor-induced "reflexive" changes in sniffing patterns in rodents can be observed $\sim 160 \mathrm{~ms}$ after stimulus onset (Johnson et al., 2003), most of the time required for the completion of discrimination tasks is probably used for OB sensory processing. Consistent with previous reports, two recent 
studies reported mean sampling times during simple odor discrimination tasks of $\sim 270 \mathrm{~ms}$ in rodents (Uchida and Mainen, 2003; Abraham et al., 2004). However, when the difficulty of the task was increased, the mean sampling time in the go/no-go paradigm increased by $\sim 100 \mathrm{~ms}$ (Abraham et al., 2004). With the two-alternative-choice paradigm, processing time was also longer (by $\sim 35 \mathrm{~ms}$ ) with a more difficult-to-discriminate mixture (Uchida and Mainen, 2003). Thus, sampling time increases with task difficulty, as in humans (Wise and Cain, 2000). According to these studies, the longer discrimination time after $\mathrm{zVAD}$ administration is consistent with longer processing times in the OB. Interestingly, odor-evoked EOG responses, afferent inputs to the glomeruli and odorant discrimination threshold remained unaffected by our zVAD treatment. As bulbar zVAD delivery did not affect the turnover of OSNs, we conclude that the longer processing times we observed result from the increase in survival of bulbar neurons and not from any change in glomerular innervation. Furthermore, since the rate of cell death of mature adultgenerated neurons and of preexisting $\mathrm{OB}$ neurons is rather negligible in healthy mice (Winner et al., 2002; Lemasson et al., 2005; Ninkovic et al., 2007), the main target of zVAD treatment consists of the newborn neuron population. Thus, new neuron turnover is important for OB functioning. As it is difficult to determine precisely the time available for information processing in the OB circuit from the measured sampling times, we cannot rule out additional participation from downstream olfactory structures. In the go/no-go task, the delay between odor onset and receptor neuron stimulation, plus the time needed for higher cortical and motor processing, has been estimated at $\sim 70 \mathrm{~ms}$ (Abraham et al., 2004), leaving $\sim 300 \mathrm{~ms}$ for early sensory processing. Nevertheless, our findings indicate that the prevention of new cell death in the $\mathrm{OB}$ may interfere with odor-evoked activity patterns, decreasing the ease with which they can be discriminated.

\section{Early sensory information processing in the $\mathrm{OB}$ circuit}

Odorants trigger a well organized pattern of activation across the surface of the bulb and the mechanisms by which this map is transformed into temporal patterns are beginning to be unraveled (Soucy et al., 2009). According to current models, the main function of the bulbar microcircuits is to facilitate odor-specific dynamics for decorrelating sensory input patterns. Such decorrelation functions are thought to distribute clustered input patterns more evenly in the coding space, thereby optimizing the use of the coding space for discrimination and other olfactory tasks. This hypothesis is supported by the demonstration that OB inhibition is not restricted to near neighbor cells, but can extend over at least intermediate spatial ranges. Thus, lateral dendrites of bulbar output neurons project over long distances within the bulb, providing large-scale synaptic interactions with local interneurons (Shepherd et al., 2007). Their actual functional domain to produce dendrodendritic output is constantly regulated by the modulation of spike propagation along secondary dendrites (Xiong and Chen, 2002). Interestingly, mitral cell firing patterns are only controlled by a few glomeruli spatially distant and all lateral connections are not functionally equivalent (Fantana et al., 2008). The higher connectivity observed between some cells may be mediated by the widely dispersed granule cell columns, extending from the glomeruli to the deep GCL (Willhite et al., 2006). Backpropagation of action potentials in the lateral dendrites of mitral cells, together with granule cell actions on mitral cells within narrow columns forming glomerular units, may permit generation of strong local inhibition between distant mitral cells (Migliore and Shepherd, 2008). Thus, bulbar networks aim to reformat combinatorial representations so as to facilitate their readout by downstream centers. Many experiments have shown that GABAergic reciprocal inhibition contributes to the synchronization of output neuron activity (Buonviso et al., 1992; Desmaisons et al., 1999; Kashiwadani et al., 1999), mainly through granule cell activity (Lagier et al., 2004; Schoppa, 2006). Thus, by providing new GABAergic interneurons to the $\mathrm{OB}$, adult neurogenesis may modulate network synchrony leading to substantial changes in sensory information processing.

\section{Are more adult-generated neurons always better for mature circuits?}

As many of the new neurons do not survive for very long, adultgenerated neurons may support plasticity over a short timescale. Their transient existence may not necessarily decrease their functional impact. For instance, new neurons may have unique functions only when still young or immature, losing these key functions as they mature. There is already evidence to support the hypothesis that the new neurons present transient functions (Nissant et al., 2009). This suggests that the elimination of mature adult-generated neurons may increase the density of immature newly generated neurons. This hypothesis is supported by a recent report showing that olfactory learning increases the survival of young adult-generated neurons, but results in the elimination of more mature adult-generated neurons (Mouret et al., 2008). We conclude that a precise balance between new and mature adult-generated $\mathrm{OB}$ interneurons is required and is set through active selection/elimination processes.

We demonstrate here that an increase in the total number of newly generated neurons may not systematically lead to improvements in brain functions. Manipulations to increase the total number of new neurons may have positive effects on some types of behavior, but negative effects on others. Thus, despite the increasing experimental support for an influence of neurogenesis on cognitive functions, it is far from certain how these effects are translated into functional benefits.

\section{References}

Abraham NM, Spors H, Carleton A, Margrie TW, Kuner T, Schaefer AT (2004) Maintaining accuracy at the expense of speed: stimulus similarity defines odor discrimination time in mice. Neuron 44:865-876.

Abrous DN, Koehl M, Le Moal M (2005) Adult neurogenesis: from precursors to network and physiology. Physiol Rev 85:523-569.

Aimone JB, Wiles J, Gage FH (2006) Potential role for adult neurogenesis in the encoding of time in new memories. Nat Neurosci 9:723-727.

Alonso M, Viollet C, Gabellec MM, Meas-Yedid V, Olivo-Marin JC, Lledo PM (2006) Olfactory discrimination learning increases the survival of adultborn neurons in the olfactory bulb. J Neurosci 26:10508-10513.

Alvarez-Buylla A, García-Verdugo JM, Tramontin AD (2001) A unified hypothesis on the lineage of neural stem cells. Nat Rev Neurosci 2:287-293.

Buonviso N, Chaput MA, Berthommier F (1992) Temporal pattern analyses in pairs of neighboring mitral cells. J Neurophysiol 68:417-424.

Cecchi GA, Petreanu LT, Alvarez-Buylla A, Magnasco MO (2001) Unsupervised learning and adaptation in a model of adult neurogenesis. J Comput Neurosci 11:175-182.

Chaput MA, Chalansonnet M (1997) Recording the slow potentials evoked by odors in the olfactory mucosa of awake animals. J Neurosci Methods 75:193-198.

Chen M, Ona VO, Li M, Ferrante RJ, Fink KB, Zhu S, Bian J, Guo L, Farrell LA, Hersch SM, Hobbs W, Vonsattel JP, Cha JH, Friedlander RM (2000) Minocycline inhibits caspase- 1 and caspase- 3 expression and delays mortality in a transgenic mouse model of Huntington disease. Nat Med 6:797-801.

Corotto FS, Henegar JR, Maruniak JA (1994) Odor deprivation leads to reduced neurogenesis and reduced neuronal survival in the olfactory bulb of the adult mouse. Neuroscience 61:739-744. 
Cowan CM, Roskams AJ (2002) Apoptosis in the mature and developing olfactory neuroepithelium. Microsc Res Tech 58:204-215.

Desmaisons D, Vincent JD, Lledo PM (1999) Control of action potential timing by intrinsic subthreshold oscillations in olfactory bulb output neurons. J Neurosci 19:10727-10737.

Doetsch F, Hen R (2005) Young and excitable: the function of new neurons in the adult mammalian brain. Curr Opin Neurobiol 15:121-128.

Dupret D, Fabre A, Döbrössy MD, Panatier A, Rodríguez JJ, Lamarque S, Lemaire V, Oliet SH, Piazza PV, Abrous DN (2007) Spatial learning depends on both the addition and removal of new hippocampal neurons. PLoS Biol 5:e214.

Enwere E, Shingo T, Gregg C, Fujikawa H, Ohta S, Weiss S (2004) Aging results in reduced epidermal growth factor receptor signaling, diminished olfactory neurogenesis, and deficits in fine olfactory discrimination. J Neurosci 24:8354-8365.

Fantana AL, Soucy ER, Meister M (2008) Rat olfactory bulb mitral cells receive sparse glomerular inputs. Neuron 59:802-814.

Friedrich RW, Habermann CJ, Laurent G (2004) Multiplexing using synchrony in the zebrafish olfactory bulb. Nat Neurosci 7:862-871.

Gheusi G, Cremer H, McLean H, Chazal G, Vincent JD, Lledo PM (2000) Importance of newly generated neurons in the adult olfactory bulb for odor discrimination. Proc Natl Acad Sci U S A 97:1823-1828.

Johnson BN, Mainland JD, Sobel N (2003) Rapid olfactory processing implicates subcortical control of an olfactomotor system. J Neurophysiol 90:1084-1094.

Kashiwadani H, Sasaki YF, Uchida N, Mori K (1999) Synchronized oscillatory discharges of mitral/tufted cells with different molecular receptive ranges in the rabbit olfactory bulb. J Neurophysiol 82:1786-1792.

Kelsch W, Lin CW, Lois C (2008) Sequential development of synapses in dendritic domains during adult neurogenesis. Proc Natl Acad Sci U S A

Kempermann G (2008) The neurogenic reserve hypothesis: what is adult hippocampal neurogenesis good for? Trends Neurosci 31:163-169.

Kim WR, Kim Y, Eun B, Park OH, Kim H, Kim K, Park CH, Vinsant S, Oppenheim RW, Sun W (2007) Impaired migration in the rostral migratory stream but spared olfactory function after the elimination of programmed cell death in Bax knock-out mice. J Neurosci 27:14392-14403.

Kuhn HG, Biebl M, Wilhelm D, Li M, Friedlander RM, Winkler J (2005) Increased generation of granule cells in adult Bcl-2-overexpressing mice: a role for cell death during continued hippocampal neurogenesis. Eur J Neurosci 22:1907-1915.

Lagier S, Carleton A, Lledo PM (2004) Interplay between local GABAergic interneurons and relay neurons generates gamma oscillations in the rat olfactory bulb. J Neurosci 24:4382-4392.

Lemasson M, Saghatelyan A, Olivo-Marin JC, Lledo PM (2005) Neonatal and adult neurogenesis provide two distinct populations of newborn neurons to the mouse olfactory bulb. J Neurosci 25:6816-6825.

Li M, Ona VO, Guégan C, Chen M, Jackson-Lewis V, Andrews LJ, Olszewski AJ, Stieg PE, Lee JP, Przedborski S, Friedlander RM (2000) Functional role of caspase- 1 and caspase- 3 in an ALS transgenic mouse model. Science 288:335-339.

Linster C, Johnson BA, Morse A, Yue E, Leon M (2002) Spontaneous versus reinforced olfactory discriminations. J Neurosci 22:6842-6845.

Livneh Y, Feinstein N, Klein M, Mizrahi A (2009) Sensory input enhances synaptogenesis of adult-born neurons. J Neurosci 29:86-97.

Lledo PM, Gheusi G (2003) Olfactory processing in a changing brain. Neuroreport 14:1655-1663.

Magavi SS, Mitchell BD, Szentirmai O, Carter BS, Macklis JD (2005) Adultborn and preexisting olfactory granule neurons undergo distinct experience-dependent modifications of their olfactory responses in vivo. J Neurosci 25:10729-10739.

Mechawar N, Saghatelyan A, Grailhe R, Scoriels L, Gheusi G, Gabellec MM, Lledo PM, Changeux JP (2004) Nicotinic receptors regulate the survival of newborn neurons in the adult olfactory bulb. Proc Natl Acad Sci U S A 101:9822-9826.

Migliore M, Shepherd GM (2008) Dendritic action potentials connect distributed dendrodendritic microcircuits. J Comput Neurosci 24:207-221.

Miwa N, Storm DR (2005) Odorant-induced activation of extracellular signal-regulated kinase/mitogen-activated protein kinase in the olfactory bulb promotes survival of newly formed granule cells. J Neurosci 25:5404-5412.

Mouret A, Gheusi G, Gabellec MM, de Chaumont F, Olivo-Marin JC, Lledo PM (2008) Learning and survival of newly generated neurons: when time matters. J Neurosci 28:11511-11516.

Ninkovic J, Mori T, Götz M (2007) Distinct modes of neuron addition in adult mouse neurogenesis. J Neurosci 27:10906-10911.

Nissant A, Bardy C, Katagiri H, Murray K, Lledo PM (2009) Adult neurogenesis promotes synaptic plasticity in the olfactory bulb. Nat Neurosci 12:728-730.

Petreanu L, Alvarez-Buylla A (2002) Maturation and death of adultborn olfactory bulb granule neurons: role of olfaction. J Neurosci 22:6106-6113.

Rochefort C, Gheusi G, Vincent JD, Lledo PM (2002) Enriched odor exposure increases the number of newborn neurons in the adult olfactory bulb and improves odor memory. J Neurosci 22:2679-2689.

Rubin BD, Katz LC (2001) Spatial coding of enantiomers in the rat olfactory bulb. Nat Neurosci 4:355-356.

Scholz J, Broom DC, Youn DH, Mills CD, Kohno T, Suter MR, Moore KA, Decosterd I, Coggeshall RE, Woolf CJ (2005) Blocking caspase activity prevents transsynaptic neuronal apoptosis and the loss of inhibition in lamina II of the dorsal horn after peripheral nerve injury. J Neurosci 25:7317-7323.

Schoppa NE (2006) AMPA/kainate receptors drive rapid output and precise synchrony in olfactory bulb granule cells. J Neurosci 26: 12996-13006.

Shepherd G, Chen W, Willhite D, Migliore M, Greer C (2007) The olfactory granule cell: from classical enigma to central role in olfactory processing. Brain Res Rev 55:373-382.

Soucy ER, Albeanu DF, Fantana AL, Murthy VN, Meister M (2009) Precision and diversity in an odor map on the olfactory bulb. Nat Neurosci 12:210-220.

Sun W, Winseck A, Vinsant S, Park OH, Kim H, Oppenheim RW (2004) Programmed cell death of adult-generated hippocampal neurons is mediated by the proapoptotic gene Bax. J Neurosci 24:11205-11213.

Suzuki Y (2004) Fine structural aspects of apoptosis in the olfactory epithelium. J Neurocytol 33:693-702.

Tashiro A, Sandler VM, Toni N, Zhao C, Gage FH (2006) NMDA-receptormediated, cell-specific integration of new neurons in adult dentate gyrus. Nature 442:929-933.

Thompson CK, Brenowitz EA (2009) Neurogenesis in an adult avian song nucleus is reduced by decreasing caspase-mediated apoptosis. J Neurosci 29:4586-4591.

Uchida N, Mainen ZF (2003) Speed and accuracy of olfactory discrimination in the rat. Nat Neurosci 6:1224-1229.

Vassalli A, Rothman A, Feinstein P, Zapotocky M, Mombaerts P (2002) Minigenes impart odorant receptor-specific axon guidance in the olfactory bulb. Neuron 35:681-696.

Whitman MC, Greer CA (2007) Synaptic integration of adult-generated olfactory bulb granule cells: basal axodendritic centrifugal input precedes apical dendrodendritic local circuits. J Neurosci 27:9951-9961.

Willhite DC, Nguyen KT, Masurkar AV, Greer CA, Shepherd GM, Chen WR (2006) Viral tracing identifies distributed columnar organization in the olfactory bulb. Proc Natl Acad Sci U S A 103:12592-12597.

Winner B, Cooper-Kuhn CM, Aigner R, Winkler J, Kuhn HG (2002) Longterm survival and cell death of newly generated neurons in the adult rat olfactory bulb. Eur J Neurosci 16:1681-1689.

Wise PM, Cain WS (2000) Latency and accuracy of discriminations of odor quality between binary mixtures and their components. Chem Senses 25:247-265.

Xiong W, Chen WR (2002) Dynamic gating of spike propagation in the mitral cell lateral dendrites. Neuron 34:115-126.

Yamaguchi M, Mori K (2005) Critical period for sensory experiencedependent survival of newly generated granule cells in the adult mouse olfactory bulb. Proc Natl Acad Sci U S A 102:9697-9702.

Yuan J, Yankner BA (2000) Apoptosis in the nervous system. Nature 407:802-809.

Yuan J, Lipinski M, Degterev A (2003) Diversity in the mechanisms of neuronal cell death. Neuron 40:401-413.

Zhao C, Deng W, Gage FH (2008) Mechanisms and functional implications of adult neurogenesis. Cell 132:645-660. 